\title{
Importance of pre-recruitment life-history stages to population dynamics of the woolly sculpin Clinocottus analis
}

\author{
Jana L. D. Davis ${ }^{1, *}$, Lisa A. Levin ${ }^{2}$ \\ ${ }^{1}$ Scripps Institution of Oceanography, 9500 Gilman Drive, San Diego, California 92093-0218, USA \\ ${ }^{2}$ Integrative Oceanography Division, Scripps Institution of Oceanography, 9500 Gilman Drive, San Diego, \\ California 92093-0218, USA
}

\begin{abstract}
The relative influence of pre- versus post-recruitment life-history events on population size has been the subject of much recent debate. In the marine realm, much work has focused on intertidal invertebrates and on tropical reef fishes, with mixed results. We addressed this problem for a temperate intertidal fish, Clinocottus analis. Our main goal was to determine which life-history stage was most responsible for temporal changes in population size from 1996 to 2000 at 2 sites in San Diego, California, both seasonally and during the 1997 to 1998 El Niño Southern Oscillation (ENSO) event. We approached the problem using cohort analysis and matrix population modeling. Recruitment pulses were evident in population size structure for up to a year, unobscured by post-recruitment mortality, which was not density-dependent. Recruitment was not correlated to spawning adult biomass of 3 mo earlier, suggesting that egg, larval, or early post-settlement processes during those 3 mo determined the magnitude of recruitment, and ultimately, population size. Stage-structured population projection matrices were constructed to compare population growth rates and sensitivities among seasons and between climate periods (El Niño and non-El Niño). Elasticity (prospective) and decomposition (retrospective) analyses of these matrices indicated that the vital rates to which population growth rate $(\lambda)$ was theoretically most sensitive were not necessarily those responsible for observed temporal differences in $\lambda$. Although $\lambda$ was most sensitive to juvenile growth and adult survivorship, fertility (which in this model included fecundity and egg, larval, and early post-settlement survivorship), in addition to juvenile growth, drove observed seasonal differences in $\lambda$. C. analis population size decreased during the 1997 to 1998 El Niño event due to a decrease in recruitment, a decrease in batch fecundity (hydrated eggs per female) and, at 1 site, changes in juvenile survivorship. Results of the study emphasize the power of early life-history events to structure C. analis populations on both seasonal and longer timescales.
\end{abstract}

KEY WORDS: Population dynamics $\cdot$ Population matrix models $\cdot$ Elasticity analysis $\cdot$ Decomposition analysis $\cdot$ Intertidal zone $\cdot$ Clinocottus analis

\section{INTRODUCTION}

The debate about the processes controlling population size, structure, and dynamics in marine systems is still an active one (Underwood \& Denley 1984, Victor

${ }^{*}$ Present address: Smithsonian Environmental Research Center, 647 Contees Wharf Road, Edgewater, Maryland 21037, USA. E-mail: janalddavis@yahoo.com
1986, Jones 1990, Raimondi 1990, Caley et al. 1996, Hunt \& Scheibling 1997, Menge 2000). For coastal marine species, it was long believed that larval settlers were too abundant to ever be population-limiting or regulating, and that population size was determined by post-recruitment processes such as predation, competition, facilitation, or disturbance (e.g. Underwood \& Denley 1984, Connell 1985, Forrester 1990, Caley et al. 1996). More recently, however, varying degrees of 
population regulation by recruitment have been recognized for some nearshore, benthic populations (Gaines \& Roughgarden 1985, Forrester 1990, Jones 1990, Menge 2000), including sessile rocky intertidal invertebrates (e.g. Raimondi 1990), soft-sediment invertebrates (e.g. Ólafsson et al. 1994, Peterson et al. 1996) and reef fishes (e.g. Victor 1983, 1986, Forrester 1990).

Although population size may be controlled predominately by either pre- or post-recruitment processes, populations are probably affected by both (Underwood \& Denley 1984, Caley et al. 1996), depending on temporally varying population parameters such as the magnitude of recruitment (Connell 1985, Menge 2000). The most common case may be one in which both processes are important, but in which density-dependent mortality does not eliminate the signals of strong recruitment pulses. Only if all new recruits over a threshold population size died would the effects of recruitment pulses, and therefore a degree of recruitment-regulation, be eliminated (Caley et al. 1996).

Although these issues have been addressed for sessile, hard-substrate, intertidal invertebrates (Roughgarden et al. 1984, Connell 1985, Menge 2000) and subtidal reef fishes (Victor 1983, 1986, Doherty and Fowler 1984, Forrester 1990, Jones 1990, Schmitt \& Holbrook 2000), only a few studies have focused on rocky intertidal fishes (Pfister 1996, 1998). Several fundamental differences in habitat and lifestyle between these groups may influence the circumstances affecting population regulation. Populations of intertidal fishes may differ from those of subtidal reef fishes due to the more dynamic nature, especially abiotic, of the intertidal zone relative to the subtidal zone. Intertidal fishes might be expected to differ from sessile intertidal invertebrates due to their advantage of motility, which may enable a fish to escape some of the sessile organism's sources of post-recruitment mortality. For example, abiotic factors like desiccation and heat stress can cause mortality of sessile intertidal animals (e.g. Foster 1971, Lewis \& Bowman 1975, Spight 1975, Underwood 1979, Connell 1985). Although intertidal fish also face these abiotic pressures to some degree, they can lessen their exposure by altering their intertidal locations (Davis 2001).

This study addresses the relative importance of preand post-recruitment processes to the population dynamics of the southern California woolly sculpin Clinocottus analis. Populations of this sculpin were expected to differ from the previously studied north Pacific sculpins (Pfister 1996, 1997, 1998), mainly because southern California experiences less seasonality in factors like temperature than the north Pacific, which may broaden the time window for events such as growth, spawning, and recruitment. Because $C$. analis exhibits ontogenetic habitat shifts within the first few months of intertidal life (Davis 2000b), competition among young-of-the-year recruits for resources may decrease if recruitment is spaced out more evenly throughout the year. This, in turn, might diminish density-dependent juvenile mortality.

Several questions pertaining to regulation of Clinocottus analis population dynamics were addressed: (1) Did recruitment occur in pulses? If so, for how long were the recruitment pulses evident in the population? Were they obscured by density-dependent, postrecruitment mortality? (2) Could size of recruitment pulses be predicted by adult biomass? Several processes can erase relationships between spawning biomass and recruitment, including variable egg-tolarval-phase mortality (Hjort 1914, Lasker 1981) and input of recruits from non-local sources (Caley et al. 1996). (3) To which vital rates (growth, survivorship, and fertility) was population growth rate potentially most sensitive? Do changes in these rates cause observed seasonal and interannual variation in population growth rate? These questions were addressed using elasticity and decomposition analyses of matrix population models (Caswell 1989), which have been successfully applied to other taxa to determine prospective (potential) effects and retrospective (observed) effects of vital rate changes (Levin \& Huggett 1990, Levin et al. 1996, Horvitz et al. 1997). In the present study, prospective (elasticity) and retrospective (decomposition) analyses were used to test the hypothesis that, similar to tidepool sculpins in the north Pacific (Pfister 1996), population growth rate was most sensitive to variation in early adult survivorship. (4) Is the sensitivity of population growth rate $(\lambda)$ to a vital rate related to the vital rate's temporal variability? Pfister (1998) suggested that the demographically most important processes, those to which population growth rate is most sensitive, are the least variable processes. Pfister argued that, because a population's probability of extinction is sensitive to variations in population growth rate, natural selection should lead to systems in which population growth rate varies as little as possible. As a result, population growth rate should not be sensitive to changes in lifehistory parameters that are the most variable. (5) How do seasonal and interannual (El Niño Southern Oscillation [ENSO]) environmental variation influence population dynamics? Factors that affect the processes controlling population size and structure are likely to change over time (Fox \& Gurevitch 2000). For example, adult survivorship may differ during different climate regimes, such as those that are associated with ENSO. In such a case, the relative importance of recruitment versus post-recruitment processes could change over time depending on climate. C. analis 
population size is known to have declined during the 1997 to 1998 El Niño event (Davis 2000a). In the current study, we determined whether pre-recruitment or post-recruitment events were the sources of the ENSO variation in population size.

\section{MATERIALS AND METHODS}

Study sites and species. Populations of Clinocottus analis were studied at 2 sites in San Diego, California, USA: False Point (FP) and Ocean Beach (OB). FP, where the predominant rock type is conglomerate sandstone, is located at the southern end of the rocky La Jolla headland $\left(117.3^{\circ} \mathrm{W}, 32^{\circ} 49^{\prime} \mathrm{N}\right)$. Farther south is the smooth sandstone site of $\mathrm{OB}\left(117.3^{\circ} \mathrm{W}, 32^{\circ} 45^{\prime} \mathrm{N}\right)$, at the northern end of the rocky cliffs of the Point Loma peninsula. The 2 sites are separated by an $8 \mathrm{~km}$ stretch of sandy beach.

Clinocottus analis inhabits the rocky intertidal zone during its entire life except for a planktonic larval stage of approximately 2 mo in southern California (Wells 1986) and up to $40 \mathrm{~d}$ in northern California (Blizard 2000). During this time, larvae are more abundant in shallow water $(15 \mathrm{~m})$ than father offshore $(22$ to $75 \mathrm{~m}$ depths) and more abundant near rocky tidepool regions than beaches (Feeney 1992). At a size of 12 to $25 \mathrm{~mm}$, larvae settle from the plankton into tidepools. They mature within a few months, at a size of 50 to $60 \mathrm{~mm}$ total length (TL) (Williams 1957, Wells 1974, J.L.D.D. unpubl. data) and can live up to 8 yr (Wells 1986).

Clinocottus analis is found in the intertidal zone predominantly within 30 to $90 \mathrm{~cm}$ above MLLW (Davis 2000b). Individuals move to increasingly larger, deeper, lower intertidal tidepools with greater amounts of loose cobble as they grow (Davis 2000b). Despite ontogenetic habitat shifts, fish maintain a home range of tidepools to which they return or in which they stay during consecutive low tides (Williams 1957, Richkus 1978, Yoshiyama et al. 1992).

The strong homing tendencies of Clinocottus analis permitted the resampling of populations at FP and OB in fixed sets of tidepools over time. In fall 1996, sets of 55 and 50 study pools were chosen and mapped at FP and $\mathrm{OB}$, respectively. Pools at the 2 sites ranged from $-6 \mathrm{~cm}$ below to $113 \mathrm{~cm}$ above MLLW, were from 4 to $45 \mathrm{~cm}$ deep, and had surface areas ranging from 0.23 to $13.65 \mathrm{~m}^{2}$ (Davis 2000b). Because the pools were selected to be an approximately representative subsample of all available pools, the size structure of $C$. analis measured at a site was assumed to reflect the size structure of the population (juvenile through adult stages).

Data collection. Fish were censused quarterly in the FP tidepools from November 1996 to August 1999 and in the OB tidepools from November 1996 to August 2000. The quarterly census schedule included sampling dates during November, February, May, and August of each year, with the exception of 1999 spring sampling at $O B$, which occurred in June instead of May. In addition to regular seasonal sampling, all pools at FP and OB were also sampled in June 1998, October 1998, and March 1998, and all OB pools were sampled in March 2000 and July 2000. A subset of the 55 FP pools was sampled in October 1996, June 1997, October 1997, January 1998, January 1999, April 1999, and July 1999 in order to keep closer track of cohorts. Data from these additional sampling months were not used in construction of population matrix models.

Sculpin abundance and size were measured by collecting all fish in each pool. Pools were drained by bailing or by siphoning, using hoses with mesh-covered openings. Rocks were removed, and crevices were searched for fish. Total lengths (TL) of all fish were measured to the nearest mm. From February 1998 to March 1999 and from August 1999 to August 2000, the gender of mature fish was also noted. After measurement, rocks were replaced, the pool refilled, and the fish returned. All pools within a site were sampled in 1 to $6 \mathrm{~d}$. Data were collected only during the day and only during tides lower than $30 \mathrm{~cm}$ above MLLW.

An important assumption of the study is that any immigration of juveniles or adults to the study area is offset by equal emigration of the same size classes out of the study area. Migration was thought to be minimal because Clinocottus analis has strong homing tendencies (Williams 1957, Richkus 1978, Yoshiyama et al. 1992), and because other studies of tidepool sculpins have reported little migration, even when accounting for emigration and immigration (Pfister 1996). Even if some migration occurred, low alongshore variability in population structure (indicated by the similarity in population structure between the 2 study sites [Davis 2000a]) suggests that neighboring populations were unlikely to serve as sources or sinks of particular size classes. Therefore, lack of emigration and immigration measurements probably did not produce much bias.

Cohort survivorship. Clinocottus analis recruits in pulses, like most temperate coastal species (Pfister 1997), allowing identification and tracking of cohorts from size-frequency histograms constructed with field data. These cohorts settle over the course of several weeks, followed by a stretch of few or no recruits for several more weeks to months before the next recruitment pulse begins (e.g. Fig. 1). Using histograms only from census periods in which all pools at a site were sampled, and considering only cohorts whose recruitment period had ended, the number of individuals within each cohort was counted. Monthly survivorship 


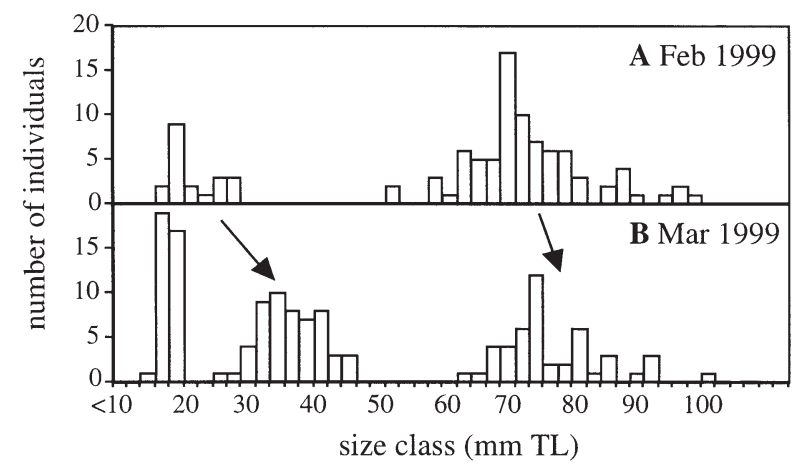

Fig. 1. An example of cohort identification: size-frequency (total length, TL) histograms showing the Clinocottus analis population at Ocean Beach in (A) February 1999 and (B) March 1999. Arrows: track cohorts through time

$(S)$ of a cohort $i$ during a period from time $t$ to time $t+1$ was calculated as:

$$
S_{i}=\left(n_{i_{(}(t+1)} / n_{i_{(t)}}\right)^{(1 / T)}
$$

where $n_{i_{(t)}}$ is the number of fish in the cohort at time $t$, $n_{i_{(t+1)}}$ is the number of fish in the cohort surviving to time $t+1$, and $T$ is the number of months between censuses. Least-squares regression was used to test whether a cohort's survivorship $\left(S_{i}\right)$ was a function of the size of its fish. Cohorts occurring during the juvenile ( $\leq 55 \mathrm{~mm} \mathrm{TL})$ and adult (>55 $\mathrm{mm} \mathrm{TL}$ ) phases were analyzed separately. In these analyses, $S_{i}$ values for all cohorts during the juvenile or adult phase were regressed against the average size of fish in the cohort.

Batch fecundity. In order to compare relationships between female size and fecundity at different times, batch fecundity of $9,7,7$, and 8 females collected from a site $0.5 \mathrm{~km}$ north of FP was measured in January 1998, April 1998, January 1999, and April 1999, respectively. Batch fecundity was defined as the number of hydrated eggs ready to be spawned that are carried by a female at any one time. Effort was made to collect females spanning the entire adult size range available during each of the 4 sampling periods. Ovaries from each female were separated and wet-weighed. The number of hydrated eggs within the larger ovary was counted, then the ratio of number of hydrated eggs in the larger ovary to ovary weight was used to estimate the total number of hydrated eggs per female.

Regressions between female ovary-free wet wt (g) and number of hydrated eggs were calculated for the 4 periods in which egg data were collected. Sample sizes were low but adequate, producing $\mathrm{r}^{2}$ values between 0.75 and 0.99. Analysis of covariance (ANCOVA) was used to determine whether the relationship between female weight and egg number changed over time. One female in January 1998 and 2 in April 1999 did not carry hydrated eggs (possibly because they had already spawned) and therefore were omitted from the analysis.

Population abundance statistics. Linear regression analysis was used to determine whether cohort size (the number of fish in a cohort) at time $t+1$ could be predicted from cohort size or mass at a previous time $t$. First, we tested whether the number of individuals in a newly recruited cohort was correlated with the number of individuals in that cohort 3, 6, 9 and 12 mo later, or whether post-recruitment processes obscured the expected relationship. Second, we tested the hypothesis that adult biomass at time $t$ was correlated with the number of new recruits at time $t+1$. Because Clinocottus analis has a 1 mo egg stage followed by a 2 mo larval stage (Hubbs 1966, Wells 1986), 3 mo was deemed an appropriate time step. Adult biomass was calculated using a weight-TL regression calculated from 34 fish collected between January 1998 and April 1999 $\left(\mathrm{r}^{2}=0.97, \mathrm{p}<<0.001\right)$ :

$$
\text { weight }=0.284 \mathrm{e}^{0.037 \mathrm{TL}}
$$

Recruitment in the present study was defined as the number of new juveniles settling between censuses separated by 3 mo (Caley et al. 1996). Early postsettlement processes that occurred before censuses could not be evaluated in this study and may have introduced a bias (Keough \& Downes 1982, Hixon \& Carr 1997).

Matrix population models. Population growth rates were calculated for Clinocottus analis populations using 3 mo time increments. Stage-based population matrix models, generated separately for the 2 sites, follow Caswell (1989). Models were constructed with 3 stages based on fish size: juvenile (J) (new recruits to $55 \mathrm{~mm}$ TL); early adult (A1) (56 to $75 \mathrm{~mm}$ TL); and late adult (A2) (>75 mm TL) (Fig. 2). The division between J and A1 stages was based on the onset of female maturity determined by gonad analyses described above and from Wells (1986). The division between A1 and A2 stages was defined as the approximate size of a $1 \mathrm{yr}$ old fish.

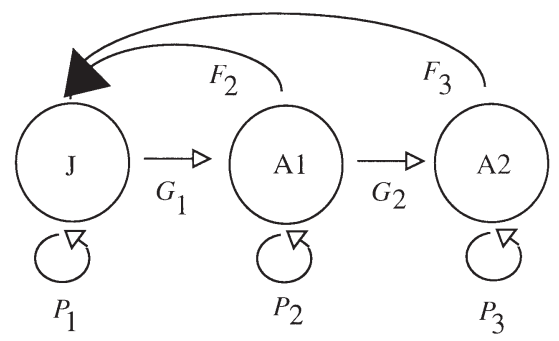

Fig. 2. Clinocottus analis. Life cycle diagram used to construct stage-based population matrix models. J, A1, A2: juvenile, early adult, and late adult life-history stages, respectively; $G_{i}$ : probability of growing to the next life-history stage during the next model time step; $P_{i}$ : probability of surviving but staying in the same stage; $F_{i}$ : contribution of offspring to the juvenile stage at the next time step (where $i=1,2$, or 3 ) 
Separate matrices were constructed for each 3 mo time period. The 3 mo time step was chosen to represent the time between spawning and larval recruitment (1 mo egg phase and 2 mo larval phase). Each matrix corresponded to 1 of 4 periods: (1) November to February, (2) February to May, (3) May to August, and (4) August to November, with the addition of a lateJune to early-October matrix in 1998. In total, 12 seasonal matrices were constructed using data from November 1996 to August 1999 at FP, and 16 matrices were constructed using data from November 1996 to August 2000 at OB (Appendix 1).

Matrices were structured as:

$$
n_{t+1}=A n_{t}
$$

or

$$
\left(\begin{array}{l}
\mathrm{J}_{t+1} \\
\mathrm{~A} 1_{t+1} \\
\mathrm{~A} 2_{t+1}
\end{array}\right)=\left(\begin{array}{lll}
P_{1} & F_{2} & F_{3} \\
G_{1} & P_{2} & 0_{3} \\
0 & G_{2} & P_{3}
\end{array}\right) \times\left(\begin{array}{l}
\mathrm{J}_{t} \\
\mathrm{~A} 1_{t} \\
\mathrm{~A} 2_{t}
\end{array}\right)
$$

such that:

$$
\begin{gathered}
\mathrm{J}_{t+1}=\left(P_{1} \times \mathrm{J}_{t}\right)+\left(F_{2} \times \mathrm{A} 1_{t}\right)+\left(F_{3} \times \mathrm{A} 2_{t}\right) \\
\mathrm{A} 1_{t+1}=\left(G_{1} \times \mathrm{J}_{t}\right)+\left(P_{2} \times \mathrm{A} 1_{t}\right)
\end{gathered}
$$

and

$$
\mathrm{A} 2_{t+1}=\left(G_{2} \times \mathrm{A} 1_{t}\right)+\left(P_{3} \times \mathrm{A} 2_{t}\right)
$$

where $G_{i}$ represents the probability of surviving and growing from stage $i$ to stage $i+1$ in the 3 mo time interval, $P_{i}$ is the probability of surviving but staying in the same stage during the 3 mo time interval, and $F_{i}$ is the contribution by adults in stage $i$ at time $t$ to the juvenile stage at time $t+1$ (where $i=1,2$, or 3 ). Growth $\left(G_{1}\right.$ and $\left.G_{2}\right)$ and survivorship $\left(P_{1}, P_{2}\right.$, and $\left.P_{3}\right)$ matrix entries were calculated from the field data described above. Sites were analyzed separately, but vital rates were calculated for Clinocottus analis individuals combined from all pools at a site. Sculpin cohorts were readily followed through time. Individual growth over a 3 mo time interval, or the fraction of individuals in a stage at time $t$ advancing to the next stage at time $t+1$, was calculated by comparing size-frequency histograms at times $t$ and $t+1$. The proportion of individuals advancing from stage $i$ to stage $i+1$ over a 3 mo period $\left(G_{i}\right)$ was defined as:

$$
G_{i}=g_{i} / n_{i(t)}
$$

where $g_{i}$ is the number of advancing individuals, and $n_{i(t)}$ is the number of individuals in stage $i$ at time $t$.

$P_{1}, P_{2}$, and $P_{3}$ values, or the proportion of individuals that survived the 3 mo period but did not grow to the next stage, were also determined by comparing sizefrequency histograms at times $t$ and $t+1$. Survivorship $\left(P_{i}\right)$ values were calculated as:

$$
P_{i}=\left(n_{i(t+1)}-g_{i}\right) / n_{i(t)}
$$

where $n_{i_{(t+1)}}$ is the number of individuals in stage $i$ that survived the 3 mo period. In the equation for $P_{3}, g_{3}=0$ because there was no higher stage to which individu- als could grow; individuals either remained in the A2 stage or died.

Fertility matrix entries $\left(F_{i}\right)$ were calculated using the number of new recruits at time $t+1$ and the number of eggs produced per time period. The latter parameter was estimated using the batch fecundity-female size relationships described above. Data for all females collected during the 4 time periods were combined to obtain 1 regression equation with an $\mathrm{r}^{2}$ of 0.97 ( $\mathrm{p}<$ 0.001):

$$
O=18.54 \mathrm{e}^{0.037 \mathrm{TL}}
$$

where $O$ is the number of eggs carried by a female and TL is the total length of the female. This equation was then used to calculate the number of eggs potentially produced by the sculpin population during each census period. Ideally, separate equations specific to each census period should have been used, especially since fecundity-size relationships differed slightly among time periods; however, fecundity data were only collected during 4 of 16 census periods. Instead of using specific equations for these 4 censuses and the average regression equation for the rest, we used the average equation for all. When egg number estimates produced by the 2 equations (average and specific census period) were compared for those periods for which we had fecundity information, we found that the 2 estimates never differed by more than $10 \%$. For example, when applied to the winter 1998 FP census, the average equation yielded an estimate of 8716 eggs and the specific winter 1998 equation yielded an estimate of 7969 eggs, a $9 \%$ difference. The average equation applied to winter $1999 \mathrm{FP}$ data resulted in an estimate of 29328 eggs, $5 \%$ lower than the specific winter 1998 regression estimate of 30891 .

For census periods in which gender information was recorded, the number of eggs produced by each female was calculated. For months in which gender data were not collected, the number of eggs produced by each individual was calculated as if the individual were female, then multiplied by 0.58 to account for the fact that on average $58 \pm 10 \%$ (mean \pm SD) of all fish were female during periods when gender information was collected.

$F_{2}$ and $F_{3}$ entries were calculated to incorporate egg production as well as survivorship to the juvenile stage at the next time step, 3 mo later:

$$
\begin{aligned}
& F_{2}=S_{\mathrm{e}} \times O_{\mathrm{A} 1} \times \mathrm{A} 1^{-1} \\
& F_{3}=S_{\mathrm{e}} \times O_{\mathrm{A} 2} \times \mathrm{A} 2^{-1}
\end{aligned}
$$

where $O_{\mathrm{A} 1}$ and $O_{\mathrm{A} 2}$ are the number of eggs produced by all A1 and A2 females present at time $t$, respectively, determined from the average regression between egg number and female size from January 1998 to April 1999, and $S_{\mathrm{e}}$ is the probability of 1 egg surviv- 
ing and becoming a new recruit after a 3 mo period. $S_{\mathrm{e}}$ was calculated as:

$$
S_{\mathrm{e}}=R_{t+1} /\left(O_{\mathrm{A} 1}+O_{\mathrm{A} 2}\right)
$$

where $R_{(t+1)}$ is the number juveniles recruiting to the population after $3 \mathrm{mo}$. To construct these equations, we assumed that egg viability did not depend on adult stage, and that A1 and A2 eggs had the same probability of survivorship. Because Clinocottus analis has not been observed to guard its eggs (Wells 1974), this assumption may be realistic. Therefore:

$$
\begin{aligned}
& F_{2}=\left(R_{t+1} /\left(O_{\mathrm{A} 1}+O_{\mathrm{A} 2}\right)\right) \times O_{\mathrm{A} 1} \times \mathrm{A} 1^{-1} \\
& F_{3}=\left(R_{t+1} /\left(O_{\mathrm{A} 1}+O_{\mathrm{A} 2}\right)\right) \times O_{\mathrm{A} 2} \times \mathrm{A} 2^{-1}
\end{aligned}
$$

Of all the matrix elements, the $F_{2}$ and $F_{3}$ terms are most sensitive to measurement error because they depend on the largest number of parameters and assumptions. Estimates of fertility matrix entries $\left(F_{i}\right)$ assume closed populations, an assumption that is invalid for many coastal populations (Caley et al. 1996). We did not account for non-local recruitment for 2 reasons. First, evidence suggests that while planktonic, Clinocottus analis and other cottid larvae are not transported like passive particles but remain close to their parent source by remaining close to the bottom for much of the larval phase (Feeney 1992, R. Blizard pers. comm.). As a result, C. analis recruits may be more locally derived (within several $\mathrm{km}$ ) and their populations relatively more closed than those of coastal species with more dispersive larvae. Second, populations at the 2 study sites have a very similar structure over time (Davis 2000a and present Fig. 10). Therefore, even if San Diego C. analis (sub)populations do exchange larvae among sites, so that one population's recruits may not be derived from its own adults, local fecundity and recruitment magnitude would not be mathematically decoupled. That is, the ratios of eggs to juveniles in the entire metapopulation and within each subpopulation are likely to be similar.

As indicated by Eqs. (14) \& (15), each fertility matrix entry $\left(F_{i}\right)$ contains several components. Error in only some of these components affects estimates of $F_{i}$. For example, $F_{i}$ is insensitive to measurement error in spawning that is proportional across A1 and A2. If all adults spawned more than once at the beginning of a 3 mo period, doubling $O_{\mathrm{A} 1}$ and $O_{\mathrm{A} 2}$, then estimates of egg-larval survivorship $\left(S_{\mathrm{e}}\right)$ would decrease, but the $F_{2}$ and $F_{3}$ terms would not change. Therefore, although Clinocottus analis spawning frequency is unknown (Wells 1986), estimates of $F_{i}$ are not affected. $F_{i}$ equations are, however, slightly sensitive to which female size-egg number regression equation is used to calculate fecundity. The average regression equation applied to the winter $1998 \mathrm{FP}$ census produces an $F_{2}$ of 0.50 and an $F_{3}$ of 1.61 , whereas the specific winter
1998 egg number regression produces an $F_{2}$ of 0.51 and an $F_{3}$ of 1.58. $F_{i}$ equations are also sensitive to measurements of the number of new recruits at time $t+1,\left(R_{t+1}\right) . F_{i}$ might be inaccurate if the assumption of coupled fecundity-recruitment is invalid, if the egglarval period is prolonged for more than $3 \mathrm{mo}$, or if the number of new recruits is miscounted.

Analysis of population matrices. Population growth rate $(\lambda)$ was calculated using Matlab to determine the eigenvalue structure of each seasonal matrix. Elasticity analysis was used to quantify the sensitivity of $\lambda$ to hypothetical proportional changes in each of the 7 matrix elements $\left(P_{1}, P_{2}, P_{3}, G_{1}, G_{2}, F_{2}\right.$, and $F_{3}$ ) (Caswell 1989, Horvitz et al. 1997). Elasticity $(E)$ of a matrix element $\left(a_{i j}\right)$ was defined as a proportional version of sensitivity $(S)$ of $\lambda$ to changes in that matrix element $\left(a_{i j}\right)$ (de Kroon et al. 1986):

$$
E_{i j}=\left(a_{i j} / \lambda\right) \times S_{i j}
$$

where $\lambda$ is the first eigenvalue of the matrix. $S_{i j}$ was calculated as:

$$
S_{i j}=\left(v_{i} W_{j}\right) /<W, v>
$$

Here, $w$ is the first right eigenvector of the matrix, $v$ is the first left eigenvector, $\langle W, v\rangle$ is the scalar product of those vectors, $w_{j}$ is the $j$ th element of the right eigenvector, and $v_{i}$ is the $i$ th element of the right eigenvector (Caswell 1989).

Retrospective decomposition analyses were used to determine which matrix elements were responsible for observed temporal differences in $\lambda$ (Caswell 1989). In the first of these analyses, differences in $\lambda$ between each quarterly matrix and the average matrix for the entire study period were 'decomposed' into contributions by each of the 7 matrix elements. Contribution $(C)$ of a matrix element $\left(a_{i j}\right)$ to quarterly (seasonal) differences in $\lambda$ was calculated as:

$$
C_{i j}=\left(a_{i j}{ }^{(k)}-a_{i j}{ }^{(\cdot)}\right) \times\left. S_{i j}\right|_{\left(\mathrm{A}^{(k)}+\mathrm{A}^{(\cdot)}\right) / 2}
$$

where $a_{i j}(k)$ is the value of matrix element $a_{i j}$ of the $k$ th quarterly matrix, $a_{i j}{ }^{(\cdot)}$ is the average $a_{i j}$ calculated over the entire study period, and $S_{i j}$ is the sensitivity of $\lambda$ to element $a_{i j}$ evaluated using an average of the $k$ th and the overall average matrix. $C_{i j}$, then, is simply the product of the deviation of $a_{i j}$ from the average $a_{i j}$ for the entire period and the sensitivity of $\lambda$ to average $a_{i j}$ (Caswell 1989).

In the second analysis, causes of differences in $\lambda$ between El Niño and non-El Niño periods were identified. Prior to decomposition, the 3 quarterly matrices of the El Niño period (August 1997 to May 1998) (Davis 2000a) were combined into 1 matrix, as were the 3 post-El Niño August 1998 to May 1999 matrices. Consecutive August to November $\left(A_{\mathrm{AN}}\right)$, November to February $\left(A_{\mathrm{NF}}\right)$, and February to May $\left(A_{\mathrm{FM}}\right)$ matrices were 
combined into 1 August to May matrix $\left(A_{\mathrm{AM}}\right)$, using the formula (Caswell 1989):

$$
A_{\mathrm{AM}}=A_{\mathrm{FM}} \times A_{\mathrm{NF}} \times A_{\mathrm{AN}}
$$

We then used Eq. (18) to calculate the contribution of element $a_{i j}$ to differences in $\lambda$ between the two 9 mo periods. Here, $a_{i j}{ }^{(k)}$ is the value of matrix element $a_{i j}$ of the either the first or second August to May matrix $\left(A_{\mathrm{AM}}\right)$, and $a_{i j}{ }^{(\cdot)}$ is the average $a_{i j}$ of the $2 A_{\mathrm{AM}}$.

Temporal dynamics of population parameters. Seasonality was tested in the 7 matrix entries $\left(F_{2}, F_{3}, P_{1}\right.$, $G_{1}, P_{2}, G_{2}$, and $\left.P_{3}\right)$, total juvenile survivorship $\left(P_{1}+G_{1}\right)$, total adult survivorship $\left(P_{2}+G_{2}\right)$, total growth of juveniles $\left(T G_{1}\right)$, total growth of $\mathrm{A} 1$ fish $\left(T G_{2}\right)$, and $\lambda$. Total growth of juveniles and adults was defined as the proportion of surviving fish that grew to the next stage:

$$
T G_{i}=G_{i} /\left(P_{i}+G_{i}\right)
$$

The seasonal cycle was characterized using day length values. Day length was treated as a general proxy for the suite of seasonal environmental changes, including temperature and sea level (Davis 2000a). Months were ranked in order of least to most daylight on a scale of 1 (December) to 12 (June). Each sculpin sampling period was then assigned a light value which was the average light rank of all months within the period. For example, any November to February sampling period had a light value of 2.5, the average of November (3), December (1), January (2), and February (4).

Because population parameters might follow a seasonal pattern offset from the light cycle, 12 lags of $1 \mathrm{mo}$ intervals were applied to the light values, from 0 to 11 mo. Regression analysis revealed, for those parameters that had a seasonal component, which lag provided the best fit, as defined by the highest positive correlation coefficient (r). $P_{i}, G_{i}, T G_{i}$, and $\left(P_{i}+G_{i}\right)$ terms were arcsine-square root-transformed prior to regression analysis. $F_{2}$ and $F_{3}$ values were log-transformed.

Differences in $\lambda$, recruitment, fertility, and survivorship between El Niño and non-El Niño periods were tested using 2-way Model III (mixed effects) analyses of variance (ANOVAs) with unequal replication. Differences in $\lambda$, recruitment, fertility, and survivorship were each tested with a separate ANOVA, with site (FP and $\mathrm{OB}$ ) as a random factor and climate regime (El Niño and non-El Niño) as a fixed factor. Because the El Niño period did not include a May to August quarter, data from all May to August non-El Niño quarters were excluded from the analysis.

Density-dependence of population parameters. The density-dependence of total juvenile survivorship $\left(P_{1}+\right.$ $\left.G_{1}\right)$, total A1 survivorship $\left(P_{2}+G_{2}\right)$, total A2 survivorship $\left(P_{3}\right)$, total juvenile growth $\left(T G_{1}\right)$, and total A1 growth $\left(T G_{2}\right)$ was tested. Simple linear regression analysis was used to test for relationships between each parameter and total population size at time $t$.

\section{RESULTS}

\section{Predicting cohort size}

Clinocottus analis recruitment peaks of varying magnitudes were observed in all 4 seasons at FP and OB. Adult biomass at time $t$ was not correlated with the number of new recruits at time $t+1$ ( 3 mo later), indicating that within the range of observed adult population sizes, recruitment variability was not a function of adult biomass $\left(\mathrm{r}^{2}=0.07, \mathrm{p}=0.773\right.$ at $\mathrm{FP}, \mathrm{r}^{2}=0.05, \mathrm{p}=$ 0.471 at $\mathrm{OB})$. The number of fish in a cohort when its fish averaged $30 \mathrm{~mm}$ TL was significantly correlated with the number of fish in the cohort 3,6 , and 9 mo later at FP and 3, 6, and 12 mo later at OB (Fig. 3), indicating that the signal of recruitment peaks was detectable in the population for at least 9 to $12 \mathrm{mo}$, after which cohorts were reduced to only a few individuals (Fig. 3). These results, when coupled with the lack of
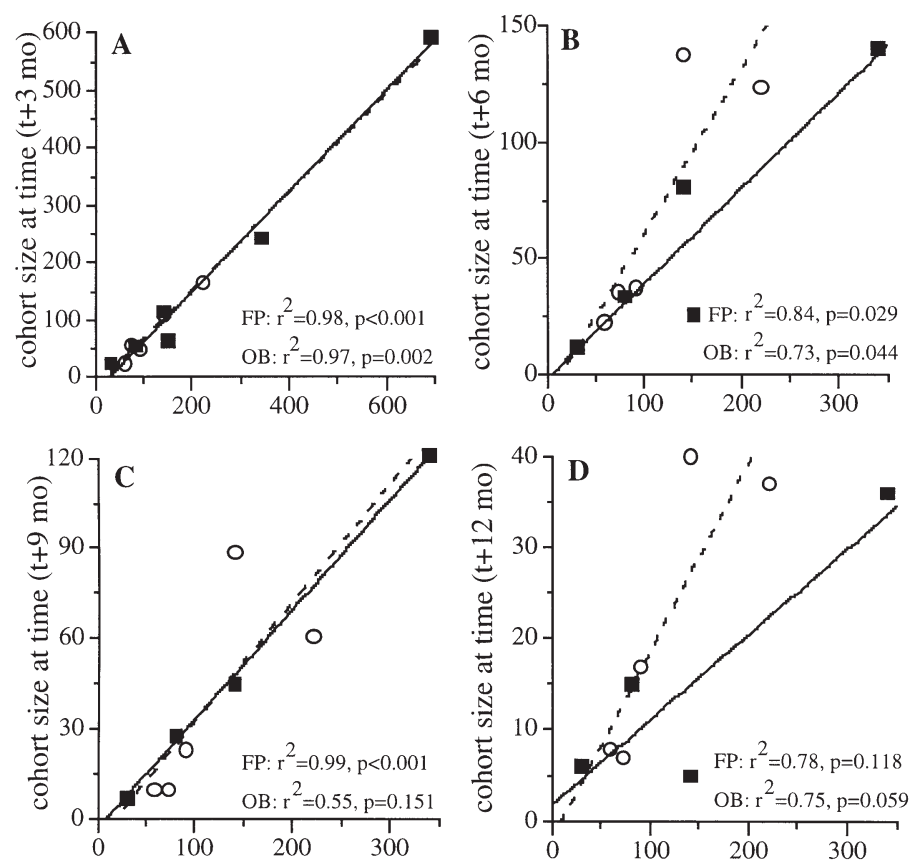

cohort size at recruitment ( $30 \mathrm{~mm} \mathrm{TL})$

False Point $\quad-\bullet-$ Ocean Beach

Fig. 3. Clinocottus analis. Number in a cohort when mean fish size is $30 \mathrm{~mm}$ versus number in the cohort: (A) 3 mo later (B) 6 mo later, (C) 9 mo later, and (D) 12 mo later. The largest cohort visible in (A) does not appear in (B) to (D) because the study ended 4 mo after its recruitment. Several other cohorts similarly disappear from the plots 

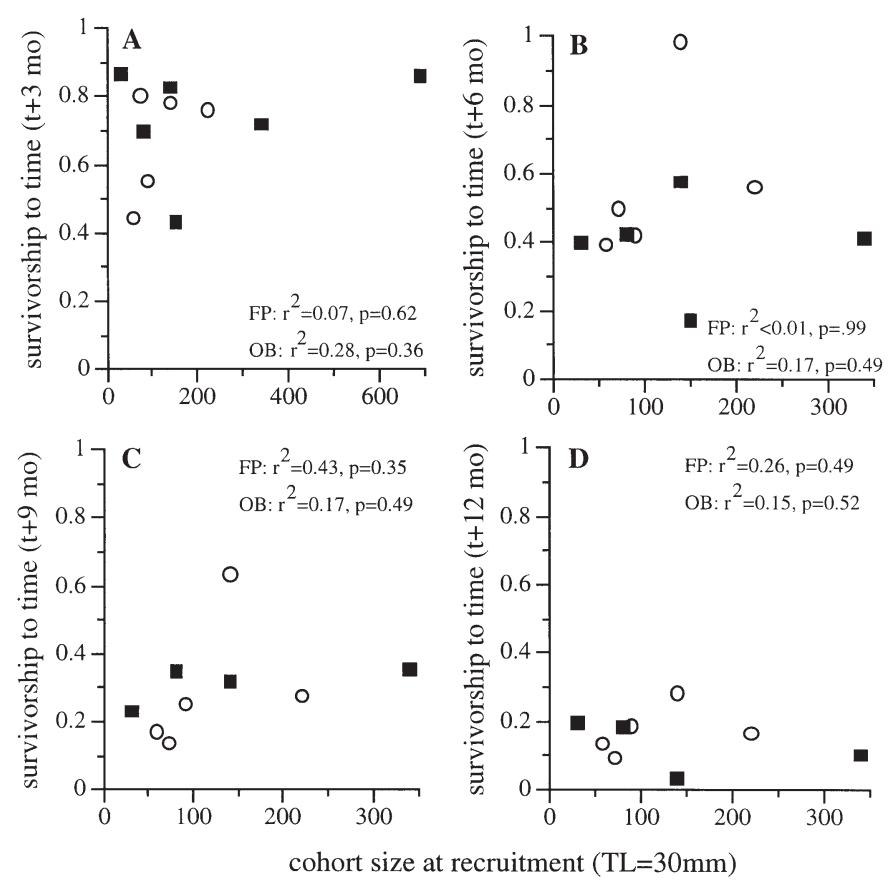

cohort size at recruitment $(\mathrm{TL}=30 \mathrm{~mm})$

- False Point o Ocean Beach

Fig. 4. Clinocottus analis. Density-independence of survivorship. Survivorship of fish in a cohort over (A) 3 mo (B) 6 mo (C) 9 mo and (D) 12 mo was not related to the number of fish that recruited to the cohort

relationship between adult biomass and recruitment, suggest that processes occurring in the egg, larval, or early post-settlement stage determine cohort size for at least the first year.

A positive relationship between the number of fish in a cohort at times $t$ and $t+1$ does not necessarily rule out density-dependent controls of mortality if, for example, the relationship is not linear. In the case of density-dependent mortality, one would expect either a significant positive or negative correlation between cohort size and the proportion of fish surviving after a certain period of time. However, no such correlation was observed in the Clinocottus analis population at either site (Fig. 4), suggesting that the processes acting to reduce cohort size after recruitment were not density-dependent. Total survivorship of juveniles $\left(P_{1}+G_{1}\right)$ and adults $\left(P_{2}+G_{2}\right)$ over a 3 mo time interval were not correlated with number of fish present at either site (Table 1), further supporting the hypothesis of density-independence. Juvenile survivorship, although not correlated with fish abundance, was correlated with fish size. Juvenile survivorship decreased with increasing fish size at both FP and OB (Fig. 5A). However, there was no relationship between fish size and survivorship within the adult size range (>55 mm TL) (regression analyses, p $>>0.05$, Fig. 5B).

Unlike survivorship, total juvenile growth $\left(T G_{1}\right.$, Eq. 20) was negatively correlated with number of fish at both FP and OB. Juveniles grew more slowly when more fish were present in the population (Table 1, Fig. 6). This relationship suggests that growth was negatively density-dependent, but is also consistent with the hypothesis that factors enhancing recruitment might also create poor growth conditions in the intertidal zone. Total early adult (A1) growth ( $T G_{2}$, Eq. 20) was not density-dependent at either site (Table 1).

\section{Population dynamics of Clinocottus analis}

Quarterly population growth rates ( $\lambda$ per $3 \mathrm{mo}$ ) varied from 0.4 to 3.6 at FP and from 0.3 to 2.1 at OB (Fig. 7). Based on prospective elasticity analyses, one might have predicted that this variation in $\lambda$ was driven by early adult dynamics. In general, $\lambda$ tended to be most sensitive to hypothetical changes in either $G_{1}$, representing survival and growth of juveniles to the A1 stage, or $\mathrm{P}_{2}$, representing survival of $\mathrm{A} 1$ fish that did not grow out of the A1 stage (Table 2, Fig. 7A-D, Appendix 2). Together, these terms explain the number of fish that accumulate in the A1 stage. Elasticity of $P_{i}$ tended to be highest during August through February, and elasticity of $G_{i}$ tended to dominate during the opposite time of year. $\lambda$ was never most sensitive to potential change in $F_{i}$, which includes both adult fertility and recruitment (Eqs. 14 \& 15).

Table 1. Clinocottus analis. Density-dependence of growth $\left(G_{1}\right.$ and $\left.G_{2}\right)$ and survivorship $\left(P_{1}\right.$ and $\left.P_{2}\right)$ at False Point and Ocean Beach (n = 12 and 16 quarterly time periods, respectively). In each linear regression analysis, vital rate values were regressed against the number of fish in the population at time $t$. Correlation coefficients $(r)$ and $p$-values are presented. Statistics for significant relationships are presented in bold. J: juvenile; A1: early adult; A2: late adult

\begin{tabular}{|lcccc|}
\hline \multirow{2}{*}{ Vital rate } & \multicolumn{2}{c}{ False Point } & \multicolumn{2}{c|}{ Ocean } \\
& $\mathrm{r}$ & $\mathrm{p}$ & $\mathrm{r}$ & $\mathrm{p}$ \\
\hline$P_{1}$ & $\mathbf{+ 0 . 5 9}$ & $\mathbf{0 . 0 2 0}$ & $\mathbf{+ 0 . 5 0}$ & $\mathbf{0 . 0 5 0}$ \\
$G_{1}$ & $\mathbf{0 . 7 2}$ & $\mathbf{0 . 0 0 9}$ & +0.02 & 0.944 \\
Total juvenile survivorship $\left(P_{1}+G_{1}\right)$ & -0.02 & 0.956 & +0.25 & 0.342 \\
Juvenile growth $\left(T G_{1}\right.$ : Eq. 20$)$ & $\mathbf{- 0 . 8 6}$ & $\mathbf{0 . 0 0 2}$ & $\mathbf{- 0 . 4 8}$ & $\mathbf{0 . 0 6 2}$ \\
$P_{2}$ & -0.32 & 0.314 & +0.16 & 0.559 \\
$G_{2}$ & +0.54 & 0.072 & -0.29 & 0.280 \\
Total A1 survivorship $\left(P_{2}+G_{2}\right)$ & -0.06 & 0.846 & -0.19 & 0.492 \\
A1 growth $\left(T G_{2}\right.$ : Eq. 20$)$ & +0.27 & 0.399 & -0.19 & 0.493 \\
A2 survivorship $\left(P_{3}\right)$ & +0.14 & 0.662 & +0.01 & 0.990 \\
\hline
\end{tabular}




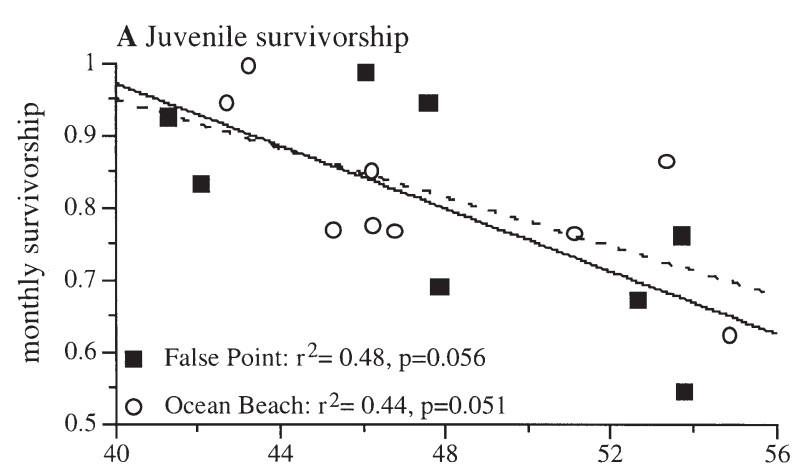

B Adult survivorship

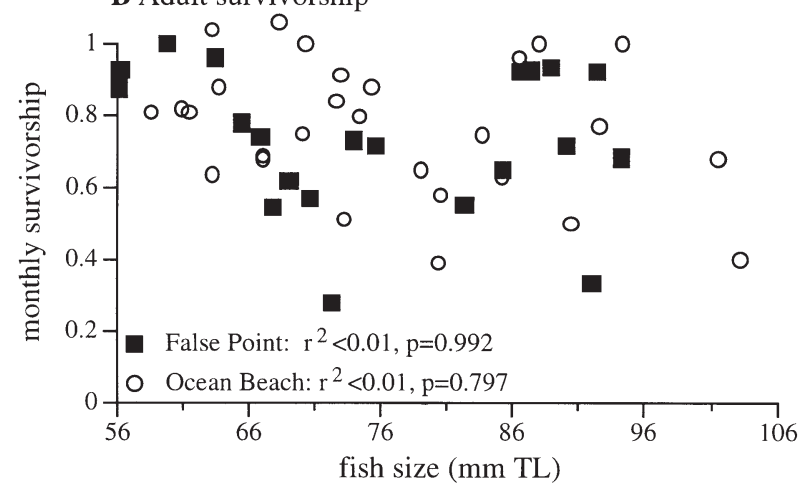

Fig. 5. Clinocottus analis. Survivorship of cohorts during (A) juvenile and (B) adult stages as a function of fish size. Size was computed as the mean of the mean size of all fish in the cohort at time $t$ and the mean size of all fish in the cohort at time $t+1$. Survivorship is measured in monthly units. Results of regression analyses ( $\mathrm{r}^{2}$ and $\mathrm{p}$-values) are presented.

Continuous line: False Point; dashed line: Ocean Beach
Decomposition analysis, which provides a retrospective look at the influence of actual changes in vital rates on $\lambda$, reveals that those life-history elements to which $\lambda$ was theoretically most sensitive were not always those elements responsible for quarterly changes in Clinocottus analis $\lambda$ during the study period (Table 2, Fig. 8E-H, Appendix 3). Although $\lambda$ was often sensitive to $P_{2}$, this term did not contribute much to temporal variation in $\lambda$. In contrast, $F_{2}$, the production of new recruits by A1 fish, overwhelmingly contributed to differences in $\lambda$ among quarters even though

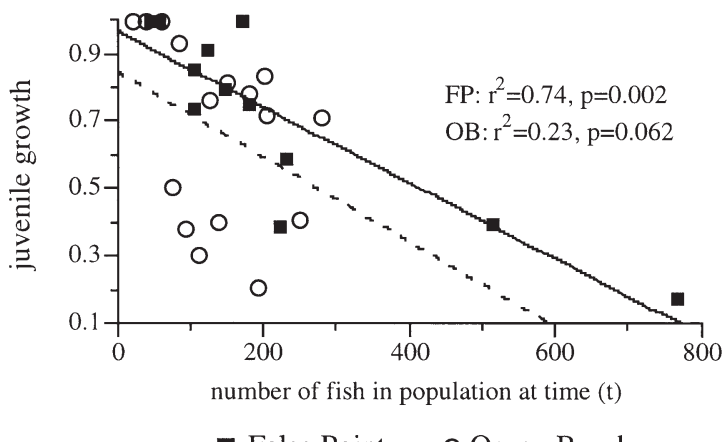

Fig. 6. Clinocottus analis. Negative density-dependence of juvenile growth at 2 sites in southern California, False Point and Ocean Beach. Juvenile growth $\left(T G_{1}\right)$ was measured from time $t$ to $t+1$ and regressed against the number of fish present in the population at time $t$. Results of regression analyses ( $\mathrm{r}^{2}$ and $\mathrm{p}$-values) are presented

Table 2. Clinocottus analis. Terms to which population growth rate $(\lambda)$ was most sensitive (highest elasticity) for each quarterly matrix and terms most responsible for differences in $\lambda$ between each quarterly matrix and the average (highest contribution). The term with the highest elasticity value and the term with the highest absolute value of contribution for each seasonal analysis are listed. If the second highest term was within $10 \%$ of the highest term, it is also listed. In the case of contribution, the sign indicates whether the term contributed positively (+) or negatively (-) to changes in $\lambda$. F2: early adult fertility; F3 late adult fertility; other abbreviations as in Table 1

\begin{tabular}{|lcccc|}
\hline Time & \multicolumn{2}{c}{ False Point } & \multicolumn{2}{c|}{ Ocean Beach } \\
& Elasticity & Contribution & Elasticity & $F_{2}(-)$ \\
Nov-Feb 1997 & $P_{2}$ & $F_{2}(-)$ & $P_{2}$ & $F_{2}(-), G_{1}(-)$ \\
Nov-Feb 1998 & $P_{3}$ & $F_{2}(-)$ & $P_{2}$ & $F_{2}(-)$ \\
Nov-Feb 1999 & $P_{2}$ & $F_{2}(-)$ & $P_{2}$ & $F_{2}(-)$ \\
Nov-Feb 2000 & & $P_{2}$ & $G_{1}(+)$ \\
Feb-May 1997 & $G_{1}, F_{2}$ & $F_{2}(-), G_{1}(+)$ & $G_{1}$ & $G_{1}(-), G_{2}(+)$ \\
Feb-May 1998 & $P_{2}$ & $F_{2}(-)$ & $G_{1}, F_{2}$ & $G_{1}(-)$ \\
Feb-May 1999 & $G_{1}, F_{2}$ & $F_{2}(+)$ & $G_{1}, F_{2}$ & $P_{3}(+)$ \\
Feb-May 2000 & & & $G_{1}, F_{2}$ & $P_{2}(-)$ \\
May-Aug 1997 & $G_{1}$ & $G_{1}(+), G_{2}(+)$ & $G_{1}$ & $G_{1}(-)$ \\
May-Aug 1998 & $G_{1}$ & $F_{2}(+), F_{3}(+)$ & $G_{1}, F_{3}$ & $P_{2}, G_{1}$ \\
May-Aug 1999 & $P_{3}$ & $F_{3}(-), G_{1}(-)$ & $G_{1}, F_{2}$ & $P_{2}(-), F_{2}(-)$ \\
May-Aug 2000 & & $P_{1}$ & $P_{3}$ & $P_{2}(+), F_{3}(-)$ \\
Aug-Nov 1997 & $F_{3}$ & $F_{2}(-)$ & $G_{1}$ & $P_{3}(+)$ \\
Aug-Nov 1998 & $P_{2}(-), G_{1}(-)$ & $G_{1}(+)$ \\
Aug-Nov 1999 & $P_{2}$ & & \\
\hline
\end{tabular}




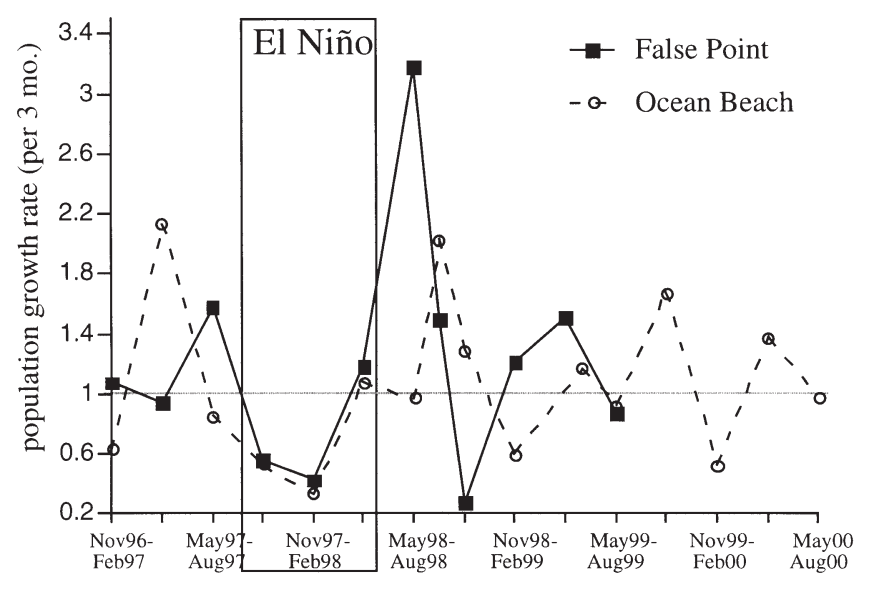

Fig. 7. Clinocottus analis. Population growth rate $(\lambda)$ from November 1996 to August 1999 at False Point and from November 1996 to August 2000 at Ocean Beach. A population growth rate $>1$ indicates a growing population, and $<1$ a shrinking population

$\lambda$ was not most sensitive to it (Table 2 ). Only $G_{1}$ had both actual and theoretical impacts on $\lambda$. ters of non El Niño years (2-way ANOVA: Table 4, Fig. 7). This decline in number and population growth rate of $C$. analis was influenced by a drop in recruitment during the Niño period. The average number of C. analis recruits during the El Niño event was about $20 \%$ of that during non-El Niño periods, a significant difference (Table 4, Fig. 10A).

The variation in number of recruits between El Niño and non-El Niño periods can be attributed in part to differences in batch fecundity between the 2 climate periods (Fig. 11). Batch fecundity-female weight relationships during the El Niño period (January and April 1998) were significantly different from those during the post-El Niño period (January and April 1999, Student's $t=4.06, \mathrm{p}<0.001$ ), but regression slopes were not different between the 2 seasons, January and April, within each climate period (1998: $t=0.31, \mathrm{p}>$ 0.50; 1999: $t=0.87, \mathrm{p}>0.20$ ). Slopes of the El Niño and post-El Niño regression lines differed in such a way that batch fecundity of large fish was most greatly influenced by climate period, whereas fecundity of smaller fish was similar between climate periods. For example, a $60 \mathrm{~mm}$ TL female was estimated to produce

\section{Seasonality}

Sculpin population dynamics were highly seasonal, although the various vital rates were not synchronized. Some vital rates, like $F_{3}$ (production of new recruits by A2 fish), were maximal in May (Fig. 9A,C). Others, like total juvenile growth, peaked in March (Fig. 9B,D). In general, growth $\left(G_{i}\right)$ and fertility/recruitment terms $\left(F_{i}\right)$ peaked from early spring to summer (Table 3). $P_{i}$ terms, which indicate survival but lack of growth, were generally highest in fall. As a result, total growth $\left(T G_{i}\right)$ was highest in late spring-summer. Total juvenile, A1, and A2 survivorship were not seasonal at either site. Seasonality in $\lambda$, therefore, appears to be driven by seasonal changes in growth and fertility, not survivorship.

\section{7 to 1998 El Niño event}

Clinocottus analis population size was significantly lower during the El Niño period than during non-El Niño periods at both OB and FP (Davis 2000a). The quarterly population growth rate of $C$. analis ( $\lambda$ per 3 mo period) was also significantly lower at the 2 sites during the 3 El Niño quarters (August 1997 to May 1998) than during the same quar-

False Point $\square$ Ocean Beach

ELASTICITY

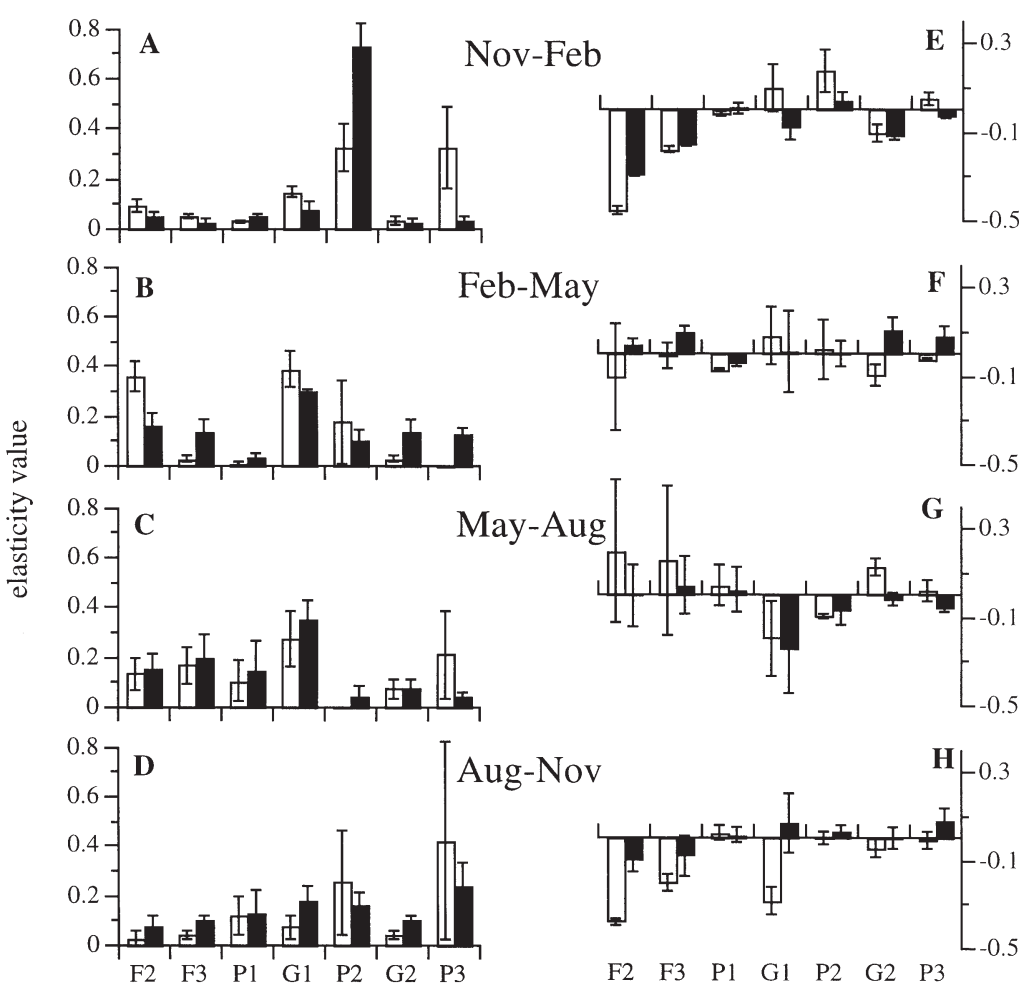

Fig. 8. Clinocottus analis. Elasticity and contribution of each matrix element (mean $\pm 1 \mathrm{SE}$ ) averaged for all years within a season at False Point and Ocean Beach 

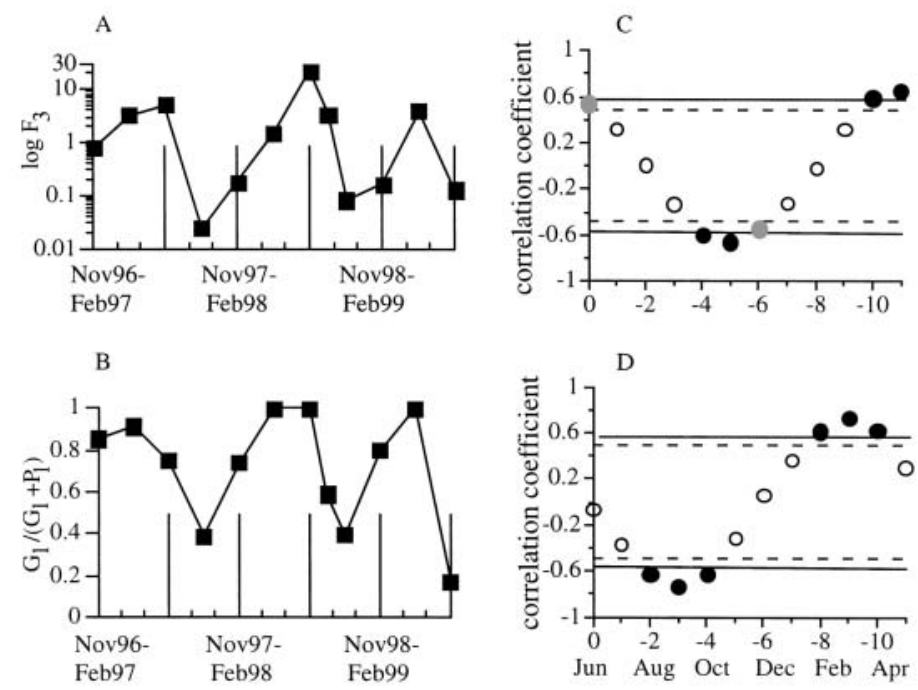

Fig. 9. Clinocottus analis. Seasonality of vital rates at False Point as determined by cross-correlation analysis. (A) $F_{3}$ and (B) juvenile growth $\left(T G_{1}\right)$ over time from November 1996 to August 1999; (C) (D) correlation coefficients of regressions between each vital rate and 11 lags of monthly daylight.

$(\bullet)$ lags that resulted in significant regressions $(\mathrm{p}<0.05)$.

(॰) lags that returned p-values between 0.05 and 0.10 ; abbreviations as in Fig. 2

161 and 170 eggs per batch during the El Niño and post-El Niño period, respectively, whereas a $100 \mathrm{~mm}$ female produced 654 eggs during the El Niño period and 920 eggs during the post-El Niño period. Other processes pertaining to fecundity also changed during the El Niño period. Values of $F_{2}$, which included both fecundity of A1 fish and recruitment of their larvae, were also lower during the El Niño period at both sites (2-way ANOVA: Table 4).

The decline in recruitment translated, after an approximately 3 mo lag, into a drop in abundance of adults in the population (Fig. 10). However, the number of adults was not immediately reduced by mortality during the El Niño event, and there were no significant differences in juvenile survivorship $\left(P_{1}+G_{1}\right)$, A1 survivorship $\left(P_{2}+G_{2}\right)$, or A2 survivorship $\left(P_{3}\right)$ between El Niño and non-El Niño periods (Table 4).

Because the number of new recruits decreased during the El Niño event but the number of adults did not, it was hypothesized that matrix elements related to recruitment and fertility $\left(F_{2}\right.$ and $\left.F_{3}\right)$ would prove to have contributed most greatly to differences in $\lambda$ between El Niño and non-El Niño time periods. At OB, the lower $F_{3}$ and $F_{2}$ of the El Niño period did contribute most greatly, in a negative direction, to the decrease in $\lambda$ during the El Niño event (Fig. 12). At FP, however, $P_{1}$, contributed most strongly to decreases in $\lambda$ during the El Niño event, followed by $\mathrm{F}_{2}$.

\section{DISCUSSION}

\section{Recruitment limitation and density-dependence}

The results of the present study contribute to the debate about the extent to which intertidal populations are limited by early (pre-recruitment) or later (older juvenile and adult) life-history events. In a

Table 3. Clinocottus analis. Seasonality of population growth rate $(\lambda)$ and vital rates (matrix elements as defined in Fig. 2 , total growth as defined in Eq. 20, and survivorship). We used cross-correlation analysis in which 11 monthly lags of day length (a proxy for season) were regressed against each vital rate. Listed here are the regression providing the highest $\mathrm{r}^{2}$ (of the 11 tried) for each vital rate and the month in which each vital rate peaked. Because day length is highest in June, a high significant lag of 0 mo translates into a vital rate peak in June, a lag of -1 indicates a vital rate peak in July, and so on. Statistics for significant relationships are presented in bold; ns: not seasonal

\begin{tabular}{|c|c|c|c|c|c|c|c|c|}
\hline \multirow[t]{2}{*}{ Vital rate } & \multicolumn{4}{|c|}{ False Point } & \multicolumn{4}{|c|}{ Ocean Beach } \\
\hline & $\begin{array}{l}\text { Peak } \\
\text { month }\end{array}$ & $\begin{array}{c}\text { Peak } \\
\text { lag }\end{array}$ & $\mathrm{p}$ & $r^{2}$ & $\begin{array}{l}\text { Peak } \\
\text { month }\end{array}$ & $\begin{array}{c}\text { Peak } \\
\text { lag }\end{array}$ & $\mathrm{p}$ & $r^{2}$ \\
\hline J growth $\left(T G_{1}\right)$ & Mar & -9 & 0.007 & 0.534 & ns & -10 & 0.167 & 0.132 \\
\hline$G_{1}$ & Mar & -9 & 0.066 & 0.299 & $\mathrm{~ns}$ & 0 & 0.828 & 0.008 \\
\hline$F_{3}$ & May & -11 & 0.012 & 0.482 & Jun & 0 & 0.013 & 0.364 \\
\hline$F_{2}$ & May & -11 & 0.033 & 0.380 & Jun & 0 & 0.002 & 0.507 \\
\hline$\lambda^{2}$ & May & -11 & 0.054 & 0.323 & ns & 0 & 0.102 & 0.179 \\
\hline A1 growth $\left(T G_{2}\right)$ & Jun & 0 & $<0.001$ & 0.712 & Jun & 0 & 0.001 & 0.543 \\
\hline$G_{2}$ & Jul & -1 & 0.005 & 0.567 & May & -11 & 0.042 & 0.264 \\
\hline$P_{1}$ & Sep & -3 & 0.041 & 0.354 & ns & -4 & 0.177 & 0.126 \\
\hline$P_{2}$ & Dec & -6 & 0.003 & 0.610 & Dec & -6 & 0.034 & 0.284 \\
\hline $\mathrm{J}$ survival $\left(P_{1}+G_{1}\right)$ & ns & -10 & 0.792 & 0.007 & ns & -9 & 0.498 & 0.033 \\
\hline A1 survival $\left(P_{2}+G_{2}\right)$ & ns & -6 & 0.153 & 0.193 & ns & -8 & 0.260 & 0.089 \\
\hline A2 survival $\left(P_{3}\right)$ & $\mathrm{ns}$ & -5 & 0.160 & 0.188 & ns & -6 & 0.551 & 0.026 \\
\hline
\end{tabular}


population limited by such factors as availability of space or food for intertidal-phase juveniles or adults, the number of recruits over a certain threshold has little effect on the total number of individuals that can be supported in the population (Roughgarden et al. 1984, Connell 1985, Menge 2000), and the mortality rate of the new recruits depends on their density.
However, where sites are undersaturated with intertidal-phase individuals, mortality rate between settlement and adulthood might have no relationship to the population density, and population size might depend primarily on the number of recruits to the intertidal phase of the population (supply-side eco$\log )$.

Table 4. Clinocottus analis. Effects of climate period and site on the following population parameters: population growth rate $(\lambda)$, number of recruits (fish $<40 \mathrm{~mm}$ TL), early adult fertility $\left(F_{2}\right)$, late adult fertility $\left(F_{3}\right)$, juvenile survivorship $\left(P_{1}+G_{1}\right)$, early adult survivorship $\left(P_{2}+G_{2}\right)$, and late adult survivorship $\left(P_{3}\right)$. For each parameter, $F$-statistics and p-values of 2-way Model III (mixed effects) analyses of variance are presented. Climate period (El Niño, EN), and non-El Niño) is treated as a fixed factor $(F=$ MSclimate/MSinteraction), and site (FP and $\mathrm{OB}$ ) as a random factor ( $F=$ MSsite/MSerror). Values in bold indicate significant results

\begin{tabular}{|c|c|c|c|c|c|c|c|c|c|}
\hline \multirow[t]{3}{*}{ Parameter } & \multirow[t]{3}{*}{ Site } & \multicolumn{2}{|c|}{ Means } & \multicolumn{6}{|c|}{ 2-way ANOVA statistics } \\
\hline & & \multirow[t]{2}{*}{$\mathrm{EN}$} & \multirow[t]{2}{*}{ Non-EN } & \multicolumn{2}{|c|}{ Climate } & \multicolumn{2}{|c|}{ Site } & \multicolumn{2}{|c|}{ Climate $\times$ Site } \\
\hline & & & & $F$ & $\mathrm{p}$ & $F$ & $\mathrm{p}$ & $F$ & $\mathrm{p}$ \\
\hline \multirow[t]{2}{*}{$\lambda$} & FP & 0.73 & 1.08 & \multirow[t]{2}{*}{18.7} & \multirow[t]{2}{*}{0.001} & \multirow[t]{2}{*}{0.21} & \multirow[t]{2}{*}{0.654} & \multirow[t]{2}{*}{0.01} & \multirow[t]{2}{*}{0.930} \\
\hline & OB & 0.65 & 1.24 & & & & & & \\
\hline \multirow[t]{2}{*}{ No. of recruits } & FP & 20 & 96 & \multirow[t]{2}{*}{118} & \multirow[t]{2}{*}{$<0.001$} & \multirow[t]{2}{*}{0.67} & \multirow[t]{2}{*}{0.419} & \multirow[t]{2}{*}{0.07} & \multirow[t]{2}{*}{0.790} \\
\hline & OB & 11 & 47 & & & & & & \\
\hline \multirow[t]{2}{*}{$F_{2}$} & FP & 0.21 & 2.99 & \multirow[t]{2}{*}{792} & \multirow[t]{2}{*}{$<0.001$} & \multirow[t]{2}{*}{0.01} & \multirow[t]{2}{*}{0.914} & \multirow[t]{2}{*}{0.01} & \multirow[t]{2}{*}{0.908} \\
\hline & OB & 0.34 & 1.73 & & & & & & \\
\hline \multirow[t]{2}{*}{$F_{3}$} & FP & 0.22 & 1.64 & \multirow[t]{2}{*}{1.19} & \multirow[t]{2}{*}{0.516} & \multirow[t]{2}{*}{4.86} & \multirow[t]{2}{*}{0.041} & \multirow[t]{2}{*}{2.85} & 0.109 \\
\hline & OB & 2.58 & 2.12 & & & & & & \\
\hline$P_{1}+G_{1}$ & FP & 0.60 & 0.69 & 2.84 & 0.227 & 1.14 & 0.301 & 0.98 & 0.335 \\
\hline & $\mathrm{OB}$ & 0.35 & 0.68 & & & & & & \\
\hline$P_{2}+G_{2}$ & FP & 0.52 & 0.44 & 1.18 & 0.518 & 1.38 & 0.256 & 0.08 & 0.780 \\
\hline & OB & 0.65 & 0.64 & & & & & & \\
\hline$P_{3}$ & FP & 0.41 & 0.40 & 0.90 & 0.598 & 0.25 & 0.627 & 1.60 & 0.223 \\
\hline & OB & 0.29 & 0.67 & & & & & & \\
\hline
\end{tabular}

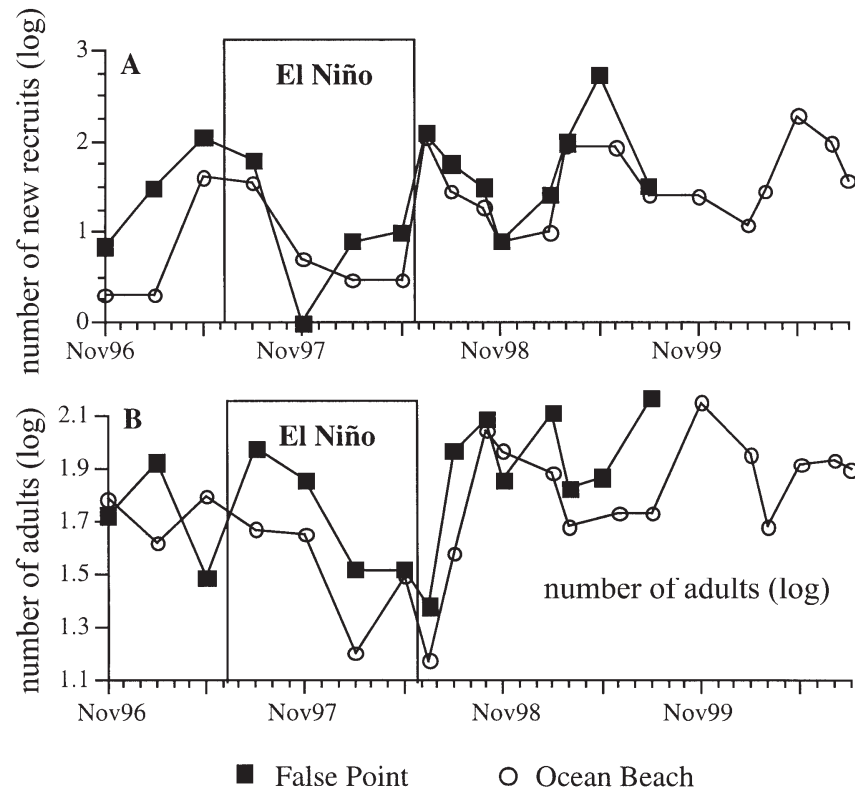

Fig. 10. Clinocottus analis. Number of $(A)$ recruits $(\leq 39 \mathrm{~mm}$ TL) and (B) adults (>55 mm TL) over time at False Point and Ocean Beach

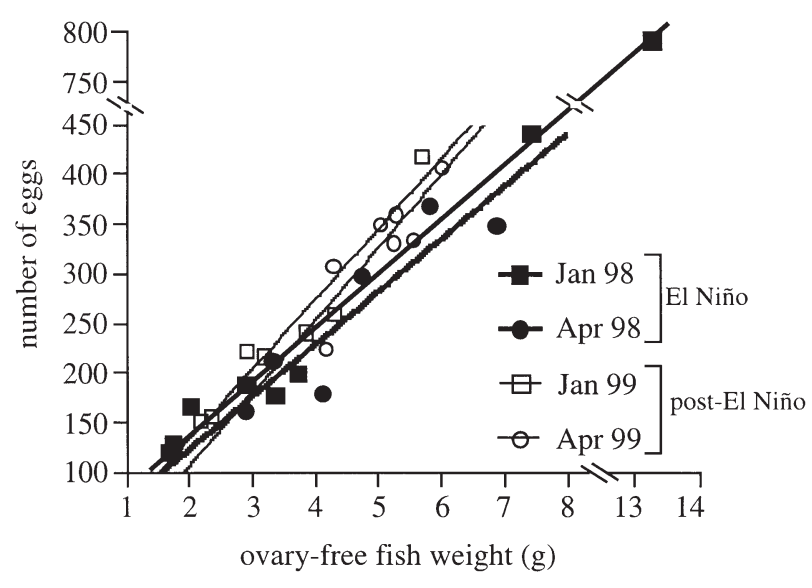

Fig. 11. Clinocottus analis. Number of eggs per female versus female wet weight (ovary-free) at 4 time periods: January 1998 (El Niño), April 1998 (El Niño), January 1999 (post-El Niño), and April 1999 (post-El Niño). Regression equations are: January 1998: $y=54 x+27, \mathrm{r}^{2}=0.99$; April 1998: $y=53 x$ $+18, \mathrm{r}^{2}=0.82$; January 1999: $y=71 x-7, \mathrm{r}^{2}=0.94$; April 1999: $y=73 x-40, r^{2}=0.75$. Analysis of covariance results indicate a significant difference in slopes between El Niño and post-El Niño relationships (see 'Results') 


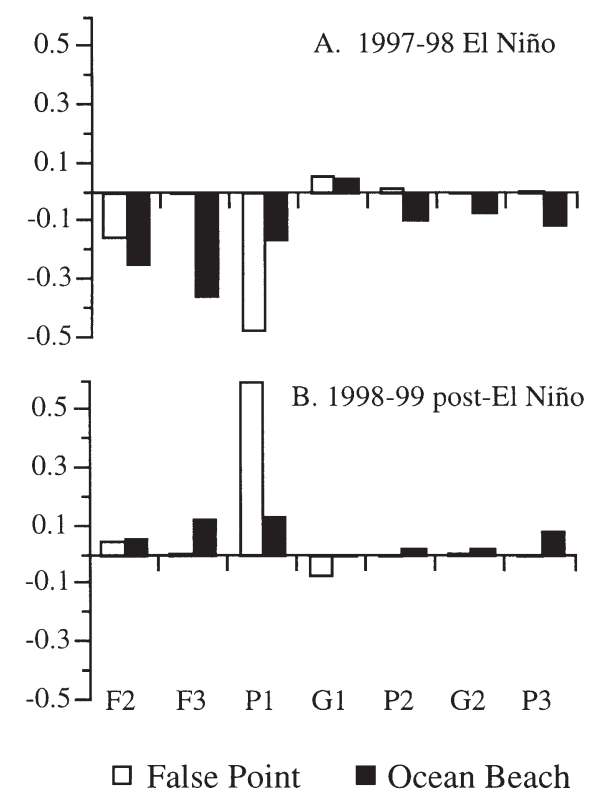

Fig. 12. Clinocottus analis. Contribution of the 7 matrix elements to differences in $\lambda$ between (A) the August 1997 to May 1998 El Niño period and (B) the August 1998 to May 1999 non-El Niño period at False Point (FP) and Ocean Beach (OB). Population growth rates during these periods were (A) 0.29 at FP and 0.32 at $\mathrm{OB}$, and (B) 1.40 at FP and 1.53 at OB. Abbreviations as in Fig. 2

The Clinocottus analis populations at FP and OB appear to be an example of the latter case, recruitment limitation. Density-dependent mortality was not observed at any life-history stage, although we must acknowledge that it could have occurred during the very early post-settlement, pre-recruitment phase (as discussed by Hixon \& Carr [1997] and Hunt \& Scheibling [1997]), a phase not included in the study. This result contrasts with those of many sessile rocky intertidal invertebrates (Connell 1985) and tidepool sculpins in Washington State, in which recruitment pulses were detectable in the population for only a few months (Pfister 1996). In San Diego, recruitment pulses of $C$. analis were evident in cohorts for at least $1 \mathrm{yr}$, past the time to maturity. Other studies of hard-bottom, nearshore fishes present results spanning the gradient from long-term persistence of recruitment pulses (Victor 1983, 1986, Doherty \& Fowler 1994) to dampening of recruitment pulses within a few months, before adulthood is reached (Pfister 1996). Persistence of recruitment pulses and density-dependent mortality are not mutually exclusive, however, and many studies of benthic fishes show that mortality is at least to some degree density-dependent (Forrester 1990, Jones 1990).

Identification of factors controlling the size of recruitment pulses is beyond the scope of this work.
However, one possible mechanism, that of direct, proportional development of recruiting cohorts from adult spawners, can be eliminated. As in many fish populations (Lasker 1981, Robertson et al. 1993), the spawning biomass of Clinocottus analis was not related to recruitment. Decoupling of recruitment and adult biomass in C. analis probably occurred at some point between spawning and settlement, although events that were post-settlement but pre-recruitment may also have contributed to this decoupling. One mechanism of the decoupling may have been temporally variable larval mortality rates, which have been noted in most fish populations (Hjort 1914, Lasker 1981, Robertson et al. 1993). Other processes that cannot be ruled out as contributing factors include temporal variability in spawning and settlement success, assuming closed or synchronous populations, as discussed above. Batch fecundity did not vary enough over time to account for the magnitude of recruitment variation observed, but spawning frequency may have.

Because recruitment pulses persisted in the population for at least $1 \mathrm{yr}$, those processes occurring between egg and recruitment that probably determined the size of the recruitment pulse had effects on the population far beyond the recruitment stage. These processes effectively controlled the cohort size for the rest of its existence. These results reaffirm the potential importance of larval supply (e.g. Eckman 1996) or early post-settlement processes (e.g. Peterson \& Summerson 1992, Peterson et al. 1996, Hunt \& Scheibling 1997) to benthic adult population structure.

As survivorship of all 3 Clinocottus analis stages (juvenile, A1 fish, and A2 fish) in San Diego appeared to be both density-independent and non-seasonal, the question remains as to what factors controlled or influenced survivorship. For juveniles, fish size played a role, with mortality increasing as juvenile size increased. This result, opposite to the typical pattern, supports a small-size refuge hypothesis and perhaps explains why $C$. analis increasingly uses structural refugia as it grows from settlement to maturity (Davis 2000b, Davis unpubl. data). By about $50 \mathrm{~mm} \mathrm{TL}$, sculpin are almost always associated with structural refugia, their structural use no longer dependent on fish size (Davis unpubl. data). Factors controlling adult survivorship remain unknown.

\section{Controls of population growth rate}

Dominance of the contribution of the $F_{2}$ term to quarterly differences in $\lambda$ (Table 3 ) is consistent with the suggestion that a post-spawning, pre-settlement, or early post-settlement process controls population size. The $F_{2}$ term includes both fecundity of the A1 female 
as well as survivorship of her offspring through the larval and early post-settlement stages until recruitment 3 months later. Differences in $F_{2}$ among time periods therefore reflect differences in early life-history processes among time periods (again assuming closed or synchronous populations). The fact that $\lambda$ was not overwhelmingly sensitive to hypothetical changes in $F_{2}$ reaffirms the importance of its variation. Because contribution is a combination of $\lambda$ 's sensitivity to a parameter and its variation (Eq. 18), $F_{2}$ therefore must have had high variability to generate such differences in $\lambda$ over time. Future studies, in which egg, larval, and early post-settlement processes are separated, would allow determination of which of the $F_{2}$ components is most important in driving temporal changes in $\lambda$.

The $P_{2}$ and $P_{3}$ terms, which represent adult survivorship but lack of growth, might have been expected to contribute significantly to temporal differences in $\lambda$. As in other studies of nearshore fishes (Lo et al. 1995, Pfister 1996), $\lambda$ was highly sensitive to hypothetical variation in early adult survivorship (high elasticity of $\lambda$ to $P_{2}$ and $P_{3}$ ). However, changes in these terms did not account for differences in $\lambda$ observed over time. This discrepancy illustrates the importance of distinguishing between those life-history traits that actually contribute to differences in $\lambda$ and those to which $\lambda$ is most sensitive. Sensitivity of $\lambda$ to a life-history parameter does not necessarily translate into effects of that parameter on $\lambda$ (Horvitz et al. 1997).

Elasticity results for Clinocottus analis in San Diego were consistent with Pfister's (1998) hypothesis that those matrix elements to which $\lambda$ is most sensitive should vary least (Fig. 13). Those elements with the lowest coefficients of variation $(\mathrm{CV})$ over time at FP $\left(G_{1}\right.$

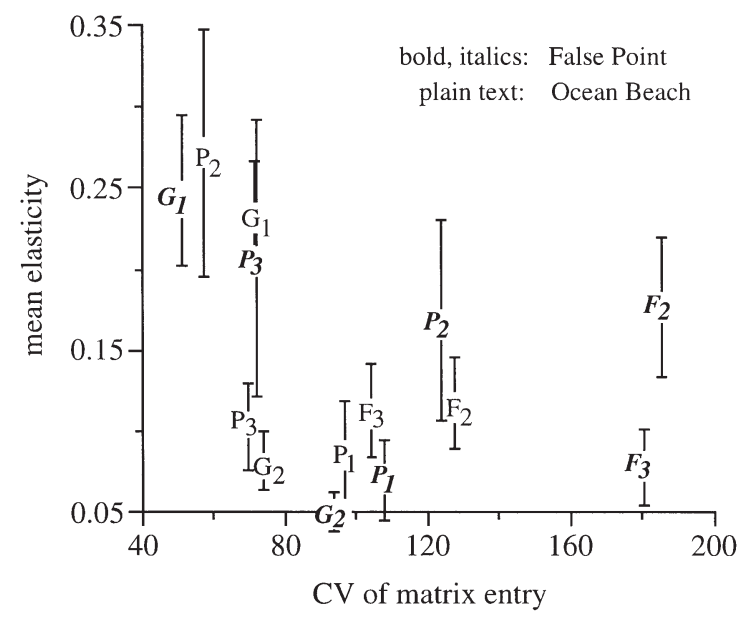

Fig. 13. Clinocottus analis. Mean elasticities ( $\pm 1 \mathrm{SD}$ ) of matrix elements and their coefficients of variation (CV) calculated using quarterly matrices over the full study period. At False Point, $\mathrm{r}^{2}=0.131$ and $\mathrm{p}=0.434$; at Ocean Beach, $\mathrm{r}^{2}=0.307, \mathrm{p}=$ 0.197. Abbreviations as in Fig. 2 and $\left.P_{3}\right)$ and $\mathrm{OB}\left(G_{1}\right.$ and $\left.P_{2}\right)$ had the highest mean elasticities. However, elements with the highest CVs $\left(F_{2}\right.$ and $\left.F_{3}\right)$ did not always have the lowest elasticities. Pfister (1998) reported that in 17 matrix population model studies, fertility elasticity was never higher than growth or survivorship elasticities. $F_{2}$ and $F_{3}$ in the present system did occasionally have higher elasticity values than $P_{i}$ or $G_{i}$ terms, especially in the winter and spring (Table 2).

\section{Temporal aspects of population dynamics}

Despite the relatively mild winters of San Diego compared to more northerly latitudes, and despite the year-round nature of Clinocottus analis recruitment (Fig. 10), seasonality of certain population parameters was observed. Most highly seasonal were growth and fertility/recruitment $\left(F_{i}\right)$. Because batch fecundity did not differ seasonally (between January and April), the driving force behind seasonality of $F_{i}$ was probably larval survivorship. $G_{i}$ and $F_{i}$ terms both contributed highly to quarterly differences in $\lambda$. Juvenile and adult survivorship were not seasonal and were inconsequential to quarterly changes in $\lambda$. These results place the southern Californian $C$. analis system between the highly seasonal north Pacific intertidal cottids and other temperate fishes (Victor 1983, Pfister 1997) and the relatively non-seasonal, tropical reef fishes (Victor 1986).

Population structure of nearshore organisms has been shown to vary on longer temporal scales, including the El Niño Southern Oscillation (Arntz \& Tarazona 1990). At the 2 sites in the present study, decreases in Clinocottus analis abundance and population growth rate during the 1997 to 1998 El Niño period may have been due in part to a decrease in fecundity, especially that of large females; however, a drop in batch fecundity probably did not account for the total El Niño reduction in recruitment. Other factors, such as lower larval survivorship, lower egg survivorship, decreased spawning frequency, or post-settlement but prerecruitment survivorship most likely contributed as well (Davis 2000a). Decomposition analyses indicate that $F_{3}$ and $F_{2}$, which include both fecundity and recruitment, contributed most to climate period differences in $\lambda$ at OB. The different result for the FP population, which implicated $P_{1}$ as the biggest contributor to climate differences in $\lambda$, is not consistent with predictions that terms incorporating recruitment $\left(F_{2}\right.$ and $F_{3}$ ) would have highest decomposition values. However, this result does emphasize the importance of relatively early, pre-maturity life-history stages. Because C. analis is the dominant member of the San Diego intertidal fish assemblage, decreases in population 
growth rate and size led to substantial changes in fish assemblage structure during the El Niño event (Davis 2000a). Thus, variability in events occurring during the early life-history of $C$. analis affects not only dynamics of the $C$. analis population, but dynamics of the entire fish assemblage as well.

\section{Conclusions}

Clinocottus analis cohort and population size variation in southern California appears to be shaped primarily by pre-recruitment events rather than by density-dependent, post-recruitment processes. Processes occurring during either the egg, larval, or early post-settlement stage determine the size of recruiting cohorts, which in turn shapes the number of adults that mature and persist in the population. Post-settlement mortality, which is high, of course still acts on the settled cohort. However, it may be controlled by forces unrelated to the population and its size. Direct measurements of larval and early benthic-stage duration, growth, and survivorship in the plankton are necessary in order to further specify which specific early lifehistory parameters are most important in determining population size.

Combined with similar information about other rocky intertidal species, both motile and sessile, these results may contribute to general ecological models about what types of populations are likely to be most severely limited by pre- versus post-recruitment processes, and under what conditions. We predict that adult motility, which allows habitat shifts in response to biotic and abiotic intertidal stresses, should play a role in determining the degree to which populations are recruitment-limited. Although the Clinocottus analis system may initially serve as a general model for other motile intertidal species, studies of other intertidal fish and invertebrate species and other taxa are required to test this prediction. In addition, further study of $C$. analis during additional El Niño events would allow ecological generalization pertaining to climate effects on population dynamics.

Acknowledgements. Many, many thanks to Erin Hubbard, Nicole Dederick, Julie Frost, Andrew Juhl, Edward Vowles, and Doug MacIntyre for dedicated field assistance. We appreciate the comments offered by Paul Smith, Dave Checkley, Paul Dayton, Trevor Price, and Clint Winant on the manuscript. This work was supported by funding awards to J.L.D.D. from the Department of Defense's Science and Engineering Graduate Fellowship Program, J. M. Hepps Graduate Fellowship Program, Mildred Mathias Foundation, PADI foundation, Sigma Xi, Sigma Delta Epsilon Graduate Women in Science, the SIO Graduate Department, and a California Sea Grant College Program (National Oceanic and Atmospheric Administration) Traineeship (project NA66RG0477 (R/C6165PD)).

Appendix 1. Clinocottus analis. Stage-based population matrix entries. Matrix entries are presented for each quarterly matrix from November 1996 to August 1999 at False Point and November 1996 to August 2000 at Ocean Beach, San Diego, California. Matrix entry abbreviations as in Fig. 2

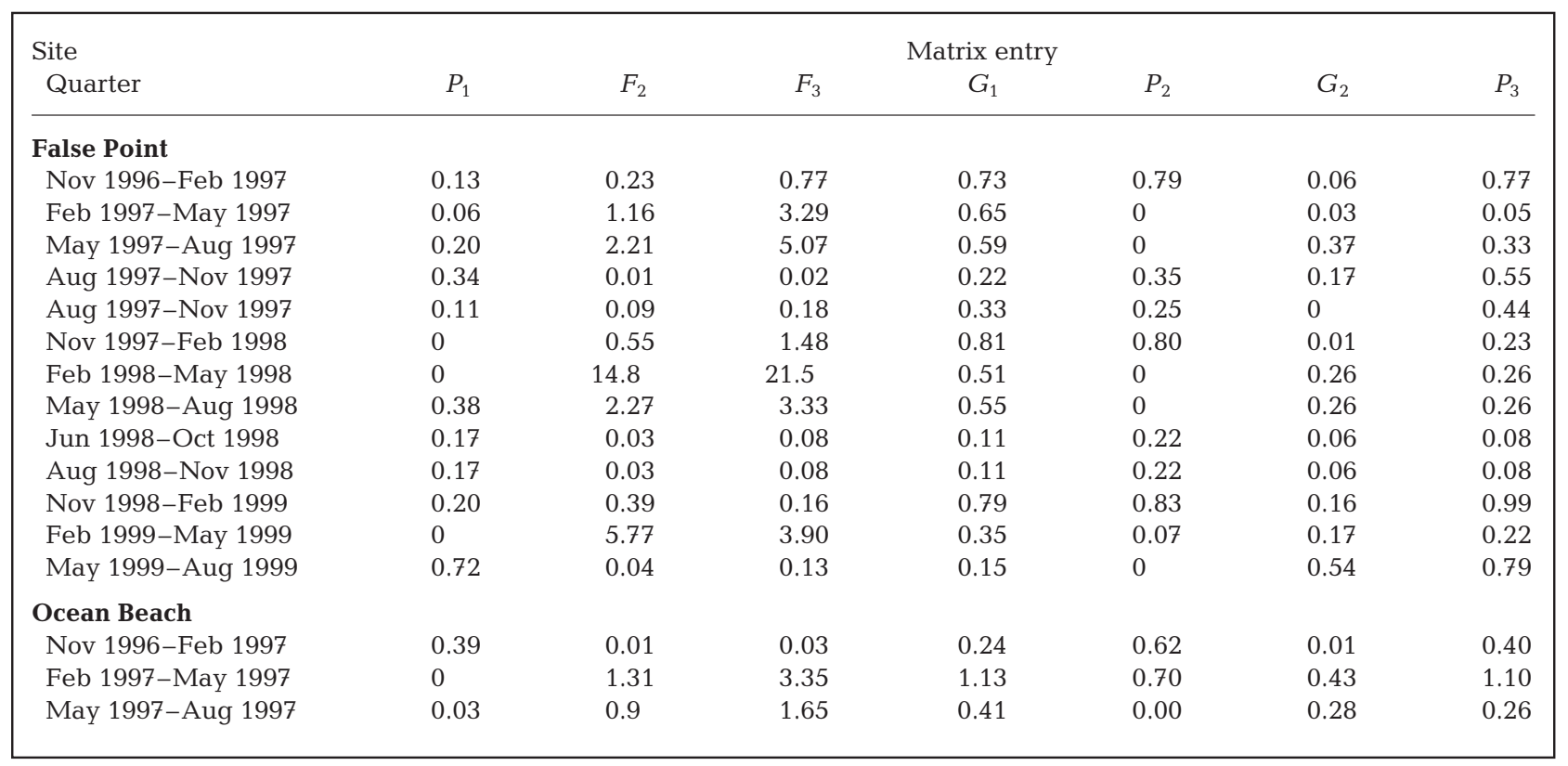


Appendix 1 (continued)

\begin{tabular}{|c|c|c|c|c|c|c|c|}
\hline $\begin{array}{l}\text { Site } \\
\text { Quarter }\end{array}$ & $P_{1}$ & $F_{2}$ & $F_{3}$ & $\begin{array}{c}\text { Matrix entry } \\
G_{1}\end{array}$ & $P_{2}$ & $G_{2}$ & $P_{3}$ \\
\hline \multicolumn{8}{|c|}{ Ocean Beach (continued) } \\
\hline Aug 1997-Nov 1997 & 0.41 & 0.02 & 0.03 & 0.18 & 0.39 & 0.41 & 0.35 \\
\hline Nov 1997-Feb 1998 & 0.16 & 0.03 & 0.07 & 0.16 & 0.31 & 0 & 0.19 \\
\hline Feb 1998-May 1998 & 0 & 0.51 & 4.92 & 1 & 0.44 & 0.56 & 1.00 \\
\hline May 1998-Aug 1998 & 0 & 6.75 & 6.16 & 0.13 & 0.00 & 0.13 & 0.13 \\
\hline Jun 1998-Oct 1998 & 0.21 & 4.95 & 6.23 & 0.55 & 0.38 & 0.15 & 0.30 \\
\hline Aug 1998-Nov 1998 & 0.09 & 0.76 & 4.15 & 0.43 & 0.39 & 0.13 & 1.00 \\
\hline Nov 1998-Feb 1999 & 0.1 & 0.08 & 0.24 & 0.46 & 0.46 & 0.11 & 0.25 \\
\hline Feb 1999-May 1999 & 0.29 & 2.73 & 0.67 & 0.19 & 0.48 & 0.28 & 0.76 \\
\hline May 1999-Aug 1999 & 0.72 & 0.34 & 0.76 & 0.19 & 0.50 & 0.13 & 0.14 \\
\hline Aug 1999-Nov 1999 & 0.22 & 1.17 & 2.82 & 0.78 & 0.57 & 0.25 & 0.89 \\
\hline Nov 1999-Feb 2000 & 0.27 & 0.05 & 0.13 & 0.19 & 0.47 & 0.04 & 0.36 \\
\hline Feb 2000-May 2000 & 0.14 & 2.35 & 1.5 & 0.44 & 0.25 & 0.24 & 0.96 \\
\hline May 2000-Aug 2000 & 0.13 & 1.97 & 1.82 & 0.31 & 0.00 & 0.26 & 0.18 \\
\hline
\end{tabular}

Appendix 2. Clinocottus analis. Elasticities of the 7 matrix entries of each quarterly stage-based population matrix. Matrices were constructed for each quarterly period from November 1996 to August 1999 at False Point and to August 2000 at Ocean Beach, San Diego, California

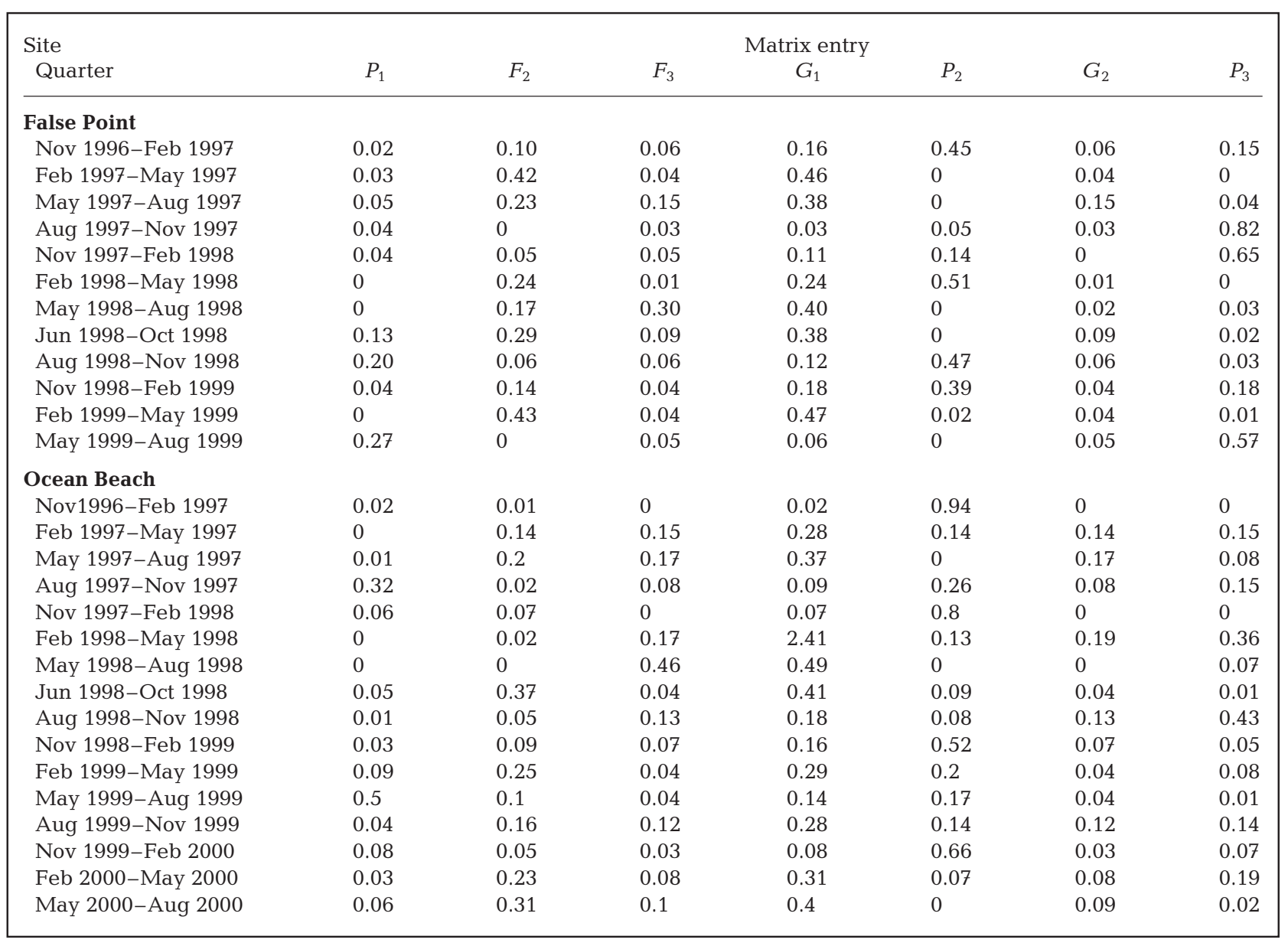


Appendix 3. Clinocottus analis. Contribution values of the 7 matrix entries obtained through decomposition analysis of each quarterly stage-based population matrix. Matrices were constructed for each quarterly period from November 1996 to August 1999 at False Point and to August 2000 at Ocean Beach, San Diego, California. Decomposition analysis revealed the contribution of a term at time $t$ to differences between the matrix of time $t$ and the average matrix for the entire period

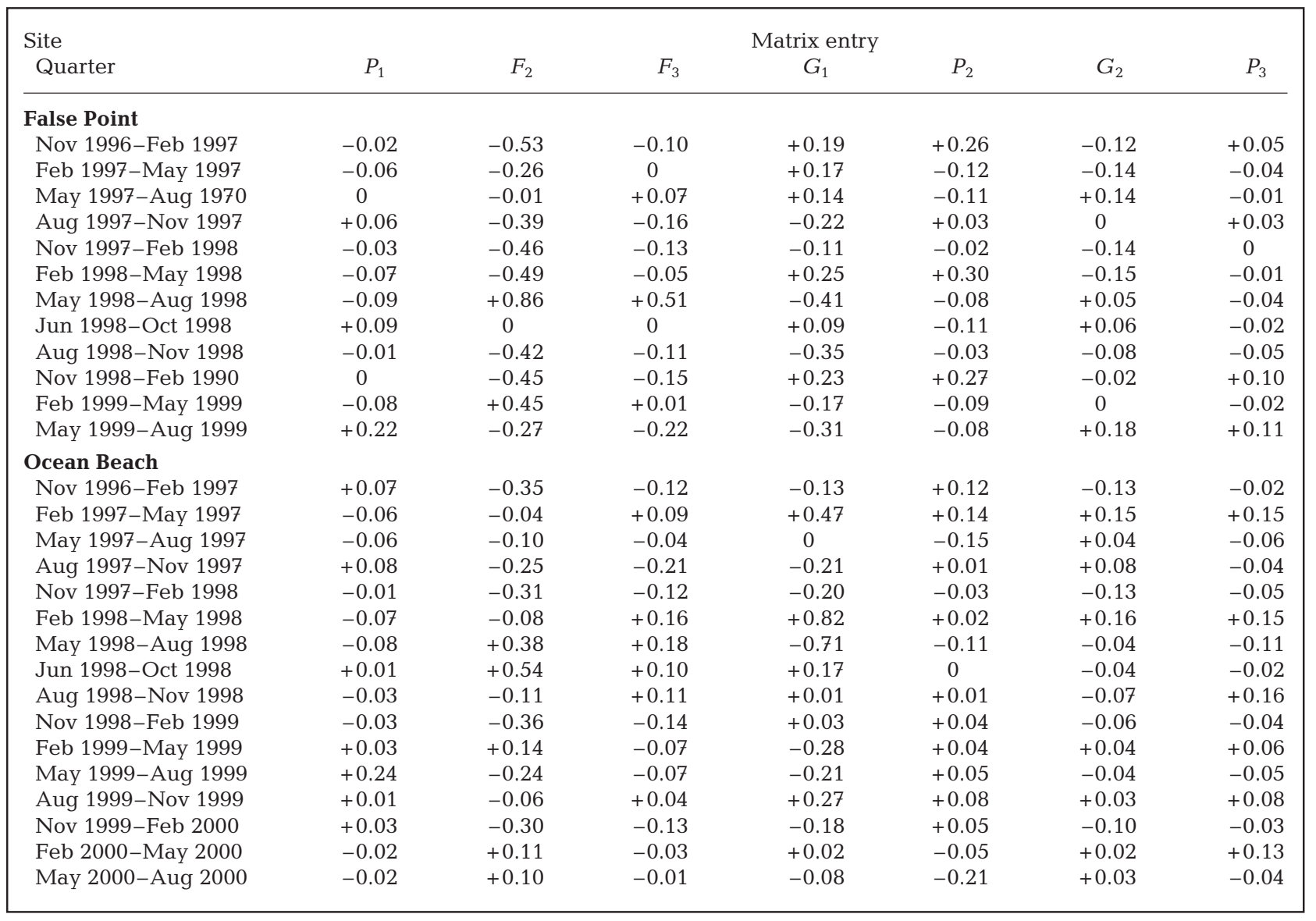

\section{LITERATURE CITED}

Arntz WE, Tarazona J (1990) Effects of El Niño 1982-83 on benthos, fish and fisheries off the South American Pacific coast. In: Glynn PW (ed) Global ecological consequences of the 1982-83 El Niño-Southern Oscillation. Elsevier, New York, p 323-360

Blizard R (2000) Life histories and otolith microstructure variation of intertidal sculpins (family Cottidae). MSc thesis, San Francisco State University, San Francisco

Caley MJ, Carr MH, Hixon MA, Hughes TP, Jones GP, Menge BA (1996) Recruitment and the local dynamics of open marine populations. Annu Rev Ecol Syst 27:477-500

Caswell H (1989) Matrix population models. Sinauer Associates, Sunderland, MA

Connell JH (1985) The consequences of variation in initial settlement versus post-settlement mortality in rocky intertidal communities. J Exp Mar Biol Ecol 93:11-45

Davis JLD (2000a) Changes in a tidepool fish assemblage on two temporal scales: seasonal and El Niño Southern Oscillation. Limnol Oceanogr 45:1368-1379

Davis JLD (2000b) Spatial and seasonal patterns of habitat partitioning in a guild of southern California tidepool fishes. Mar Ecol Prog Ser 196:253-268
Davis JLD (2001) Diel changes in habitat use by tidepool fishes. Copeia 2001:835-841

de Kroon H, Plaisier A, van Groenendael J, Caswell H (1986) Elasticity: the relative contribution of demographic parameters to population growth rate. Ecology 67:1427-1431

Doherty P, Fowler T (1994) An empirical test of recruitment limitation in a coral reef fish. Science 263:935-939

Eckman JE (1996) Closing the larval loop: linking larval ecology to the population dynamics of marine benthic invertebrates. J Exp Mar Biol Ecol 200:207-237

Feeney RF (1992) Post-yolk sac larval development of two southern California sculpins, Clinocottus analis and Orthonopias triacis (Pisces: Cottidae). Fish Bull (Wash DC) 90:454-468

Forrester GE (1990) Factors influencing the juvenile demography of a coral reef fish. Ecology 71:1666-1681

Foster BA (1971) Desiccation as a factor in the intertidal zonation of barnacles. Mar Biol 8:12-29

Fox GA, Gurevitch J (2000) Population numbers count: tools for near-term demographic analysis. Am Nat 156:242-256

Gaines S, Roughgarden J (1985) Larval settlement rate: a leading determinant of structure in an ecological community of the marine intertidal zone. Proc Natl Acad Sci USA 82:3707-3711 
Hixon MA, Carr MH (1997) Synergistic predation, density dependence and population regulation in marine fish. Science 277:946-949

Hjort J (1914) Fluctuations in the great fisheries of northern Europe viewed in the light of biological research. Rapp P-V Réun Cons Int Explor Mer 20:1-228

Horvitz CD, Schemske W, Caswell H (1997) The relative 'importance' of life-history stages to population growth: prospective and retrospective analyses. In: Tuljapurkar S, Caswell H (eds) Structured-population models in marine, terrestrial and freshwater systems. Chapman \& Hall, New York, p 241-247

Hubbs C (1966) Fertilization, initiation of cleavage, and developmental temperature tolerance of the cottid fish Clinocottus analis. Copeia 1966:29-42

Hunt HL, Scheibling RE (1997) Role of early post-settlement mortality in recruitment of benthic marine invertebrates. Mar Ecol Prog Ser 155:269-301

Jones GP (1990) The importance of recruitment to the dynamics of a coral reef fish population. Ecology 71:1691-1698

Keough MJ, Downes BJ (1982) Recruitment of marine invertebrates: the role of active larval choices and early mortality. Oecologia 54:348-352

Lasker R (1981) Factors contributing to variable recruitment of the northern anchovy (Engraulis mordax) in the California current: contrasting years, 1975 through 1978. Rapp P-V Réun Comm Int Explor Sci Mer Méditerr Monaco 178: 375-388

Levin LA, Huggett DV (1990) Implications of alternative reproductive modes for seasonality and demography in an estuarine polychaete. Ecology 7:2191-2208

Levin LA, Caswell H, Bridges T, DiBacco C, Cabrera D, Plaia G (1996) Demographic responses of estuarine polychaetes to pollutants: life table response experiments. Ecol Appl 6: 1295-1313

Lewis JR, Bowman RS (1975) Local habitat-induced variations in the population dynamics of Patella vulgata L. J Exp Mar Biol Ecol 17:165-203

Lo NCH, Smith PE, Butler JL (1995) Population growth of northern anchovy and Pacific sardine using stage-specific matrix models. Mar Ecol Prog Ser 127:15-26

Menge BA (2000) Recruitment vs. postrecruitment processes as determinants of barnacle population abundance. Ecol Monogr 70:265-288

Ólafsson EB, Peterson CH, Ambrose WG (1994) Does recruitment limitation structure populations and communities of macro-invertebrates in marine soft sediments: the relative significance of pre- and post-settlement processes. Oceanogr Mar Biol Annu Rev 32:65-109

Peterson CH, Summerson HC (1992) Basin-scale coherence of population dynamics of an exploited marine invertebrate, the bay scallop: implications of recruitment limitation. Mar Ecol Prog Ser 90:257-272

Editorial responsibility: Charles Peterson (Contributing Editor), Morehead City, North Carolina, USA
Peterson CH, Summerson HC, Luettich RA (1996) Response of bay scallops to spawner transplants: a test of recruitment limitation. Mar Ecol Prog Ser 132:93-107

Pfister CA (1996) The role and importance of recruitment variability to a guild of tidepool fishes. Ecology 77 : 1928-1941

Pfister CA (1997) Demographic consequences of within-year variation in recruitment. Mar Ecol Prog Ser 153:229-238

Pfister CA (1998) Patterns of variance in stage-structured populations: evolutionary predictions and ecological implications. Proc Natl Acad Sci USA 95:213-218

Raimondi PT (1990) Patterns, mechanisms, and consequences of variability in settlement and recruitment of an intertidal barnacle. Ecol Monogr 60:283-309

Richkus WA (1978) A quantitative study of inter-tidepool movement of the woolly sculpin Clinocottus analis. Mar Biol 49:277-284

Robertson DR, Schober UM, Brawn JD (1993) Comparative variation in spawning output and juvenile recruitment of some Caribbean reef fishes. Mar Ecol Prog Ser 94:105-113

Roughgarden J, Gaines S, Iwasa Y (1984) Dynamics and evolution of marine populations with pelagic larval dispersal. In: May RM (ed), Exploitation of marine communities. Dahlem Konferenzen, Berlin, p 111-128

Schmitt RJ, Holbrook SJ (2000) Habitat-limited recruitment of coral reef damselfish. Ecology 81:3479-3494

Spight TM (1975) On a snail's chances of becoming a year old. Oikos 26:9-14

Underwood AJ (1979) The ecology of intertidal gastropods. Oceanogr Mar Biol Annu Rev 16:111-210

Underwood AJ, Denley EJ (1984) Paradigms, explanations, and generalizations in models for the structure of intertidal communities on rocky shores. In: Strong D, Simberloff D, Abele LG, Thistle AB (eds) Ecological communities: conceptual issues and the evidence. Princeton University Press, Princeton, NJ, p 151-180

Victor BC (1983) Recruitment and population dynamics of a coral reef fish. Science 219:419-420

Victor BC (1986) Larval settlement and juvenile mortality in a recruitment-limited coral reef fish population. Ecol Monogr 56:145-160

Wells AW (1974) Life history of the woolly sculpin, Clinocottus analis (Girard), at Point Fermin, California. MSc thesis, California State University at Long Beach

Wells AW (1986) Aspects of the ecology and life-history of the woolly sculpin, Clinocottus analis, from southern California. Calif Fish Game 72:213-226

Williams GC (1957) Homing behavior of California rocky shore fishes. Univ Calif Publ Zool 59:249-284

Yoshiyama RM, Philippart MT, Moore JR, Coon CC, Schalk LL, Valpey CJ, Tosques I (1992) Homing behavior and site fidelity in intertidal sculpins (Pisces: Cottidae). J Exp Mar Biol Ecol 160:115-130

Submitted: March 7, 2001; Accepted: November 30, 2001 Proofs received from author(s): April 22, 2002 